\title{
The impact of atmospheric mineral aerosol deposition on the albedo of snow \& sea ice: are snow and sea ice optical properties more important than mineral aerosol optical properties?
}

\author{
M. L. Lamare ${ }^{1}$, J. Lee-Taylor ${ }^{2,3}$, and M. D. King ${ }^{1}$ \\ ${ }^{1}$ Department of Earth Sciences, Royal Holloway University of London, Egham, Surrey, TW20 0EX, UK \\ ${ }^{2}$ National Center for Atmospheric Research, Boulder, CO, USA \\ ${ }^{3}$ Cooperative Institute for Research in Environmental Sciences, University of Colorado, Boulder, CO, USA \\ Correspondence to: M. D. King (m.king@es.rhul.ac.uk)
}

Received: 7 July 2015 - Published in Atmos. Chem. Phys. Discuss.: 27 August 2015

Revised: 8 January 2016 - Accepted: 11 January 2016 - Published: 25 January 2016

\begin{abstract}
Knowledge of the albedo of polar regions is crucial for understanding a range of climatic processes that have an impact on a global scale. Light-absorbing impurities in atmospheric aerosols deposited on snow and sea ice by aeolian transport absorb solar radiation, reducing albedo. Here, the effects of five mineral aerosol deposits reducing the albedo of polar snow and sea ice are considered. Calculations employing a coupled atmospheric and snow/sea ice radiativetransfer model (TUV-snow) show that the effects of mineral aerosol deposits are strongly dependent on the snow or sea ice type rather than the differences between the aerosol optical characteristics. The change in albedo between five different mineral aerosol deposits with refractive indices varying by a factor of 2 reaches a maximum of 0.0788 , whereas the difference between cold polar snow and melting sea ice is 0.8893 for the same mineral loading. Surprisingly, the thickness of a surface layer of snow or sea ice loaded with the same mass ratio of mineral dust has little effect on albedo. On the contrary, the surface albedo of two snowpacks of equal depth, containing the same mineral aerosol mass ratio, is similar, whether the loading is uniformly distributed or concentrated in multiple layers, regardless of their position or spacing. The impact of mineral aerosol deposits is much larger on melting sea ice than on other types of snow and sea ice. Therefore, the higher input of shortwave radiation during the summer melt cycle associated with melting sea ice accelerates the melt process.
\end{abstract}

\section{Introduction}

The albedo of snow and sea ice has a large influence on the surface energy budget of polar regions, impacting the Earth's climate system (e.g. Barry et al., 1993; Curry et al., 1995; Jacobson, 2004; Serreze and Barry, 2005). Shortwave radiation is a key factor in the radiative balance at high latitudes, influencing the large-scale dynamics and the snow and sea ice cover. Variation in albedo is linked to several factors, such as the physical properties of snow and sea ice, morphology, surface roughness, thickness and light-absorbing impurities (e.g. Perovich et al., 1998).

The albedo of sea ice is strongly wavelength-dependent, owing to the light scattering and absorption by ice and brine. Previous studies have defined wavelength integrated and spectral albedos for a variety of snow and sea ice types (e.g. Langleben, 1969, 1971; Grenfell and Makyut, 1977; Grenfell and Perovich, 1984; Perovich et al., 1986; Perovich, 1996; Buckley and Trodahl, 1987; Grenfell, 1991; Wiscombe and Warren, 1980; Aoki et al., 1998; Hanesiak et al., 2001). Albedo is not only influenced by the physical structure of snow or sea ice but also by the amount and type of lightabsorbing impurities in the snow and sea ice (Warren and Wiscombe, 1980). Only small amounts of light-absorbing impurities are needed to achieve changes in snow or sea ice albedo (e.g. Warren and Wiscombe, 1980; Warren, 1984; Light et al., 1998; Doherty et al., 2010; Marks and King, 2014). Indeed, mass ratios of less than 1 part per million are sufficient to reduce the albedo by 5 to $15 \%$ (Warren and Wiscombe, 1980). Light-absorbing pollutants may be trans- 
ported to the Arctic as fine particulate aerosols (Shaw, 1984). Once in the Arctic, the particles are deposited onto snow or sea ice from the atmosphere by precipitation or dry deposition (Fischer et al., 2007; Doherty et al., 2010). Dust from arid and semi-arid regions is the most important source of mineral aerosols in the atmosphere (e.g. Ginoux et al., 2010). Although gravitational processes remove larger particles (Westphal et al., 1987), finer particles can be transported over great distances and in some cases reach the Arctic (Prospero et al., 2002). The two main source areas of mineral dust deposited in the Arctic are Asia and North Africa (Pacyna and Ottar, 1989; Zdanowicz et al., 1998; Bory, 2003; VanCuren et al., 2012), with an estimated flux range between 1 and $21 \mu \mathrm{g} \mathrm{cm}^{-2} \mathrm{yr}^{-1}$ (Zdanowicz et al., 1998). After mineral dust, volcanic ash is the second largest type of mineral aerosols found in the Arctic (VanCuren et al., 2012). Indeed, high-latitude volcanic eruptions frequently emit large quantities of ash into the Arctic (e.g. Stone et al., 1993; Zielinski et al., 1997; Young et al., 2012) disturbing the Arctic's climate system. The analysis of core samples in Arctic sea ice has exposed the presence of volcanic ash through traces of silicate shards and aged tephra (Ram and Gayley, 1991). However, the complex nature of volcanic eruptions makes ash deposition in the Arctic difficult to assess.

Soot and black carbon are known to absorb light strongly, thus reducing the albedo of snow and sea ice (e.g. Chýlek et al., 1983; Warren, 1984; Clarke and Noone, 1985; Warren and Clarke, 1990; Grenfell et al., 2002; Lee Taylor and Madronich, 2002; Jacobson, 2004; Flanner et al., 2007; Doherty et al., 2010; Reay et al., 2012; Ye et al., 2012; Marks and King, 2013, 2014). Field observations and modelling simulations have also shown that increases in dust deposition to snow lead to radiative forcing that affects the energy balance of snow (Woo and Dubreuil, 1985; Aoki et al., 1998; Painter et al., 2007, 2012; Huang et al., 2011; Wang et al., 2013; Zhang et al., 2013; Zhao et al., 2014; Yasunari et al., 2014). However, although anthropogenic deposits in polar snow and ice have been well characterised, studies on the effects of natural mineral aerosol deposits are more scarce. Warren and Wiscombe (1980) modelled the impact of desert dust in snow, using a compilation of optical properties present in the literature. By varying particle size and concentration, they showed that the presence of dust reduces the albedo of natural snow at shorter wavelengths (300$800 \mathrm{~nm}$ ), but the large absorption of snow in the infrared region means that the albedo of snow is insensitive to mineral dust in this region. Carmagnola et al. (2013) considered the impact of dust as well as black carbon on albedo of snow, comparing modelled results with in situ observations. They pointed out the importance of dust impurities due to their higher concentration within the snow compared with black carbon. However, Carmagnola et al. (2013) measured small concentrations of impurities to fit their observational data set, and did not take into account a larger range of values. Although volcanic ash has a local and instantaneous impact on snow and sea ice, its effects have been described as similar to soot (Warren, 1982). Warren (1982) modelled the effect of increasing Mount St. Helens ash on snow albedo for diffuse incidence. The results show a significant reduction of albedo in the visible wavelengths, and unimportant in the infrared. Conway et al. (1996) confirmed these results by showing that volcanic ash can reduce the albedo of snow up to $50 \%$. Flanner et al. (2007) and Flanner et al. (2009) developed a model that provides albedo of snow for different concentrations of black carbon, dust or volcanic ash, based on a two-stream radiative-transfer code (Toon et al., 1989). In the single-layer implementation of the model, SNICAR-online (Flanner et al., 2007), multiple snow types can be modelled by changing the snow grain radius. However, only a single type of volcanic ash derived from Patterson (1981) and combined mineral refractive indices as an approximation of mineral dust were used. Furthermore, SNICAR-online does not allow for calculations in sea ice. Impurities in sea ice have been considered by Light et al. (1998), who used a fourstream discrete-ordinates radiative-transfer model to determine how particulates (Saharan dust and sediments) alter the optical properties of sea ice. The authors analysed the sensitivity of albedo in relation to depth and thickness of a single dust layer within the ice, showing the importance of vertical distribution of deposited aerosols. Additionally, the effects of an increasing surface layer of snow containing a fixed mass of soot has been considered by Grenfell et al. (2002). However the study was limited to a single snow type and only a constant mass of soot. To the knowledge of the authors of this paper, no studies on the effects on albedo of multiple mineral dust or volcanic ash layers deposited at varying intervals in snow have been published. Studying the layering of mineral aerosol deposits in snow or sea ice enables to take into account the episodic nature of dust and volcanic ash deposition events. Moreover, the comparison of multiple sources of mineral aerosol deposits on multiple different types of snow and sea ice in an Arctic environment has not been investigated. Although Woo and Dubreuil (1985) proposed a characterisation of the relationship between dust content and Arctic snow albedo, the range of snow types and dusts was limited. Overall the understanding of the impact of mineral aerosol deposits on the albedo in the Arctic is hampered by the lack of comprehensive studies on the role of the snow or sea ice optical properties in relation to the optical properties of the mineral aerosol deposits. The work of Marks and King (2014) on the effects of the snow and sea ice type on the response of albedo to black carbon loadings suggests that the type of snow or sea ice is an important factor when considering the effects of impurities on the albedo of snow and sea ice. The conclusions from Marks and King (2014) led the authors of this paper to address the question of the importance of the type of snow or sea ice compared to the type of mineral dust or volcanic ash when evaluating the impact of mineral aerosol deposits on albedo. No studies 
investigating the effects of light-absorbing impurities on the albedo of snow and ice have examined this question.

In this work an atmospheric and snow/sea ice radiativetransfer model (TUV-snow) was used to investigate the effects of mineral aerosol deposits on snow and sea ice. The main purpose was to evaluate the impact of different mineral dusts and volcanic ashes on albedo. To do so, different mass ratios of a selection of five different mineral aerosol deposits in multiple snow and sea ice types were modelled. The thickness of a single surface layer and the vertical distribution of multiple layers loaded with mineral deposits were then varied to explore the effects of layering.

\section{Method}

The description of the method is split into three sections: the radiative-transfer model is described, followed by a detailed section on the calculation of mineral absorption crosssections and a final section describing the modelling experiment performed.

\subsection{Radiative-transfer model}

The radiative-transfer calculations of the penetration and reflection of light into snow and sea ice containing mineral aerosol deposits were performed using the Tropospheric Ultraviolet and Visible Radiation Model (TUV-snow), using the discrete-ordinates "DISORT" algorithm (Stamnes et al., 1988), as described by Lee Taylor and Madronich (2002). The model is a coupled atmospheric and snow/sea ice model that allows calculation of radiative-transfer parameters in snow and sea ice from the top of the atmosphere to the surface of the Earth and into a layer of snow or sea ice.

The model parameters simulating different types of snow and sea ice are controlled by an asymmetry factor $g$, a wavelength independent scattering cross-section, $\sigma_{\text {scatt }}$, a wavelength dependent absorption cross-section, $\sigma_{\text {ice }}$ and the sea ice or snow density (Lee Taylor and Madronich, 2002; France et al., 2011a, b; Reay et al., 2012; Marks and King, 2013, 2014).

In this study, three types of sea ice were used: first-year ice, multi-year ice and melting ice, as well as three types of snow: cold polar snow, coastal wind packed snow and melting snow. The optical and physical parameters of the selected snows and sea ice are based on field studies and summarised in Table 1. A detailed description and justification of these values can be found in Marks and King (2014).

The wavelength independent albedo of the surface under the snow and sea ice layer was fixed to 0.1 to represent seawater or soil. Irradiance reflectance at the surface was calculated to approximate albedo, represented by Eq. (1):

$A=\frac{E_{\mathrm{u}}}{E_{\mathrm{d}}}$, where $E_{\mathrm{u}}$ is the upwelling plane irradiance and $E_{\mathrm{d}}$ is the downwelling plane irradiance.

A layer of cumulus cloud was added to the model at an altitude of $1 \mathrm{~km}$ to provide diffuse illumination of the snow or sea ice surface and remove the solar zenith angle dependance. The cloud asymmetry factor $g$, was set to 0.85 , the single scattering albedo was set to 0.9999 and the optical depth was set to 32 . The atmosphere was added with an ozone column of 300 Dobsons containing no aerosols. The distance between the Earth and the Sun was fixed to $1 \mathrm{AU}$.

The modelled wavelength dependent albedo was produced over a spectrum ranging from 350 to $800 \mathrm{~nm}$ with a $1 \mathrm{~nm}$ interval.

\subsection{Optical properties of mineral dust and volcanic ash}

The snow and sea ice were modelled as media which are highly scattering and weakly absorbing of photons. The light-absorbing impurities were modelled as absorbers only and it was assumed that the ice matrix provides all the scattering. The total absorption in sea ice is

$\sigma_{\text {total }}=\sigma_{\mathrm{s}}(\lambda)+x_{\mathrm{mn}} \sigma_{\mathrm{mn}}(\lambda)$

where $\sigma_{\mathrm{S}}(\lambda)$ is the wavelength-dependant absorption crosssection of snow or sea ice, $x_{\mathrm{mn}}$ is the mass ratio of mineral aerosol deposits in the snow or sea ice and $\sigma_{\mathrm{mn}}(\lambda)$ is the wavelength-dependant absorption cross-section by mineral aerosols.

The optical constants of ice were obtained from the work of Warren and Brandt (2008). The calculation of the absorption cross-section of the mineral aerosol deposits was calculated based on the Mie theory (Bohren and Huffman, 1983) in the Mieplot program (Laven, 2006) using the BHMIE computation code (Bohren and Huffman, 1983). The resulting absorption cross-sections of the mineral aerosol deposits were used in the radiative transfer model described in Sect. 2.1.

To calculate the absorption spectra of representative mineral aerosols from a Mie Calculation, values of the imaginary refractive index, density, size and size distribution are needed. The values of the imaginary refractive index for different mineral dusts and ashes vary significantly with wavelength and the medium's mineral composition (Tegen and Fung, 1994; Sokolik and Toon, 2007). A selection of the imaginary part of the refractive index values of mineral dust found in the literature was reported by Dang et al. (2015). Three different volcanic ashes and two dusts were chosen from the literature to represent the variety of mineral aerosols deposited in the Arctic. The work of VanCuren et al. (2012), was used for Asian dust, Saharan dust, fresh volcanic tephra and aged volcanic dust plumes as the four characteristic sources of aerosols deposited at Summit, Greenland.

A representative value of the imaginary component of the refractive index of Saharan dust was calculated as the average of eight measurements of the imaginary refractive index of 
Table 1. Values of the input parameters used for snow and sea ice for the TUV-snow model, based on literature values and detailed in the work of Marks and King (2014).

\begin{tabular}{lccccccc}
\hline Snow/sea ice & $\begin{array}{c}\text { Density } \\
\left(\mathrm{kg} \mathrm{m}^{-3}\right)\end{array}$ & $\begin{array}{c}\text { Scattering cross- } \\
\text { section }\left(\mathrm{m}^{2} \mathrm{~kg}^{-1}\right)\end{array}$ & $\begin{array}{c}\text { Asymmetry } \\
\text { parameter }(g)\end{array}$ & $\begin{array}{c}e \text {-folding } \\
\text { depth }(\mathrm{cm})\end{array}$ & $\begin{array}{c}\text { Typical depth } \\
\text { modelled }(\mathrm{cm})\end{array}$ & $\begin{array}{c}\text { Minimal optical } \\
\text { thickness }(\mathrm{cm})\end{array}$ & $\begin{array}{c}\text { Equivalent snow } \\
\text { grain radius }(\mu \mathrm{m})\end{array}$ \\
\hline Cold polar snow & 400 & 20.0 & 0.89 & 15 & 40 & 45 & 85 \\
Coastal windpacked snow & 400 & 7.5 & 0.89 & 21 & 40 & 63 & 220 \\
Melting snow & 400 & 1.25 & 0.89 & 45 & 40 & 135 & 1400 \\
\hline First year sea ice & 800 & 0.15 & 0.98 & 37 & 80 & 111 & - \\
Multi year sea ice & 800 & 0.75 & 0.98 & 75 & 250 & 225 & - \\
Melting sea ice & 800 & 0.03 & 0.98 & 400 & 250 & 1200 & - \\
\hline
\end{tabular}

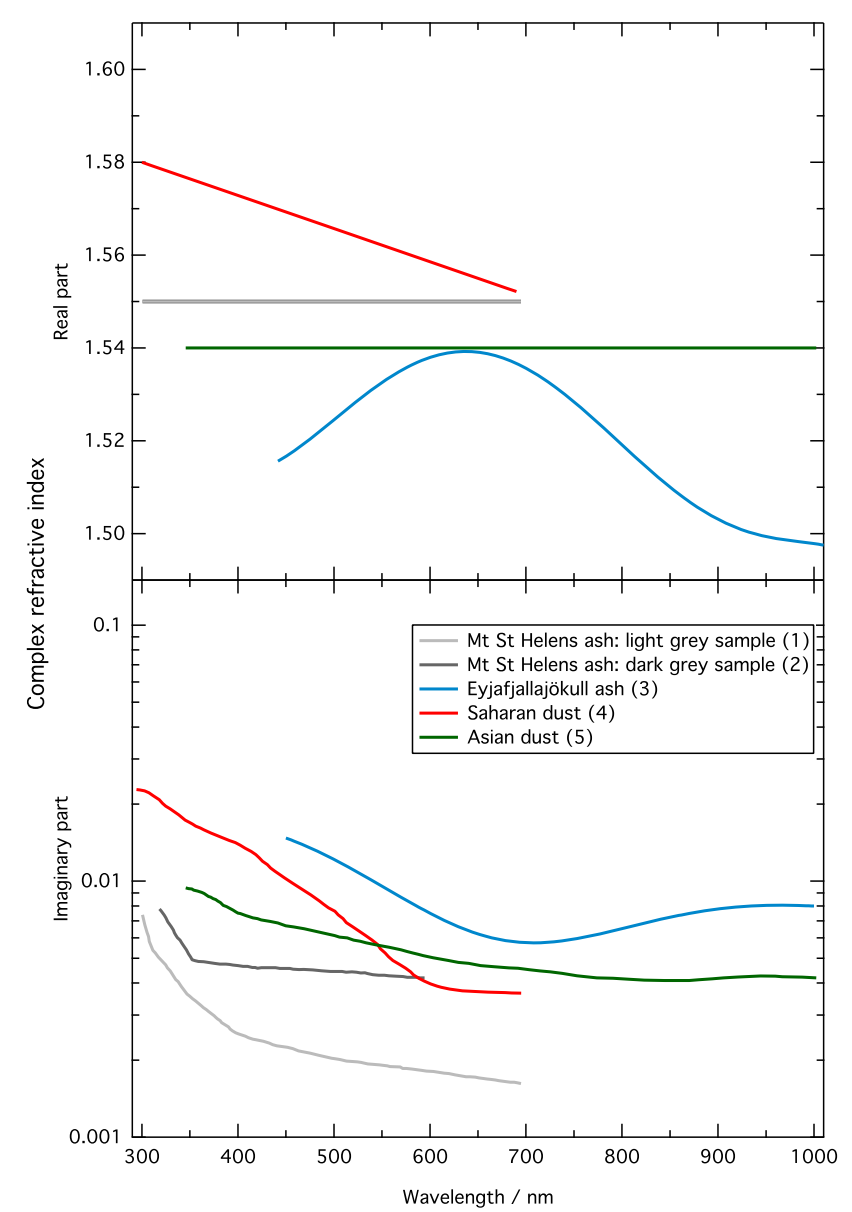

Figure 1. Complex refractive index (real and imaginary part) for mineral aerosol deposits as a function of wavelength. Values are based on work by Derimian et al. (2012) (3), Patterson and Gillette (1977) (4), Patterson (1981) (1, 2) and Sokolik et al. (1993) (5).

airborne Saharan aerosols from eight locations in the Atlantic ocean (Patterson and Gillette, 1977).

The refractive index of a characteristic central Asian dust was taken from Sokolik et al. (1993). The dust samples that Sokolik et al. (1993) collected in Tadzhikistan, are a combination of airborne dust aerosols and surface dust. The imagi- nary refractive index of the dust aerosols was used, as it represents a better approximation of transported material. Three different volcanic ash sources were used, providing a variety of mineral and thus, optical properties. Two wavelengthdependent indices of refraction of Mount St. Helens ash from the 18 May 1980 eruption were obtained from Patterson (1981). The first sample, collected in Boulder, Colorado corresponds to the first pulse of the eruption and is characterised by a dark grey colour and a high absorption coefficient in the visible wavelengths. The second sample collected in Cheney, Washington has a pale grey appearance and a lower absorption coefficient by approximately a factor of 2 (Patterson, 1981). Direct measurements of volcanic ash optical properties are scarce. Therefore an estimate of the complex refractive index of Eyjafjallajökull ash calculated by Derimian et al. (2012) was used. The weighted combination of refractive indices of each aerosol component presented a good fit with AERONET data (Derimian et al., 2012) and was more realistic than the mineral dust data of Balkanski et al. (2007) that is more widely used (Johnson et al., 2012; Turnbull et al., 2012). The values of the complex refractive index of the aerosols as a function of wavelength considered in the study presented here are in Fig. 1.

For the calculation of the extinction coefficient of lightabsorbing impurities, the mineral aerosol deposits were assumed to be spherical. Based on observations of atmospheric dust deposition in snow on the Penny ice cap on Baffin Island by Zdanowicz et al. (1998), the size distribution of the aerosols used in the calculations presented here was fixed to a $\log$ normal distribution peaking at a diameter of $2.3 \mu \mathrm{m}$ with a standard deviation of $2.1 \mu \mathrm{m}$. The size distribution corresponds to a mean value for long-range transported dusts and is similar to those measured in Greenland (Koerner, 1977). Particle densities of $2600 \mathrm{~kg} \mathrm{~m}^{-3}$ for Saharan dust (Hess et al., 1998), $2500 \mathrm{~kg} \mathrm{~m}^{-3}$ for Asian dust (Fratini et al., 2007), $2300 \mathrm{~kg} \mathrm{~m}^{-3}$ for Eyjafjallajökull ash (Johnson et al., 2012) and $1400 \mathrm{~kg} \mathrm{~m}^{-3}$ for Mt St. Helens ash (SarnaWojcicki et al., 1981) were assumed in the calculation of absorption cross-sections. The refractive index of air was used as a surrounding medium for the Mie calculations in snow whereas values for pure ice (Warren and Brandt, 2008) were used for sea ice. 


\subsection{Calculation of albedo on snow and sea ice with different mineral loading schemes}

Three types of modelling experiment were performed, as shown in Fig. 3. Initially, the surface albedo of snow and sea ice was calculated owing to increasing mineral dust mass ratios uniformly distributed in the snow and sea ice. To allow a fair comparison between the snowpack or the sea ice and the different dusts, the snow and sea ice was defined as semiinfinite, i.e. the thickness of the medium is large enough that the underlying layer does not affect the results. Secondly, the semi-infinite thickness was replaced by snowpacks and sea ice types with varying realistic thicknesses. Thirdly, the mineral aerosol deposits were constrained to layers in the snow and sea ice, as opposed to a uniform distribution. The third case reflects the episodic nature of mineral deposition.

Initially, the surface albedo of the different snow and sea ice types was calculated between 350 and $800 \mathrm{~nm}$ for an increasing mass ratio of mineral aerosol deposits. Based on the properties of the snow and sea ice used in this study, a depth of $1.5 \mathrm{~m}$ for snow and $15 \mathrm{~m}$ for ice was found to be sufficient to achieve a semi-infinite medium. Assuming the mineral aerosol deposits were distributed evenly through the medium, their mass ratio was varied between 10 and $10000 \mathrm{ng} \mathrm{g}^{-1}$. Typical mass ratio values on Baffin Island range from 78.2 to $193.2 \mathrm{ng} \mathrm{g}^{-1}$ (Zdanowicz et al., 1998), however much higher values can be found on glaciers close to volcanoes or on dust storm paths (Thorsteinsson et al., 2012; Schwikowski et al., 1995; Dong et al., 2014). Therefore a large range of values was included for completeness.

In order to determine the impact of different types of mineral aerosol deposits (with different absorption crosssections), a semi-infinite snow and sea ice cover with a uniform mass ratio of $100 \mathrm{ng} \mathrm{g}^{-1}$ for each mineral sample was modelled.

In a second step, representative thicknesses for each type of snow and ice were used based on mean values found in the literature. A depth of $40 \mathrm{~cm}$ for snow (Warren et al., 1999; Serreze and Barry, 2005; Kohler et al., 2006) representing a maximum spring Arctic value, $2.5 \mathrm{~m}$ for multi-year and melting sea ice (Bourke and Garrett, 1987; Laxon et al., 2003; Weeks, 2010) and $80 \mathrm{~cm}$ for first-year sea ice (Weeks, 2010) were chosen. The albedo of the layer under the sea ice or snow was set to 0.1 to simulate a strongly absorbing medium similar to water or soil. Albedo, as a function of an increasing mass ratio of Asian mineral dust, was calculated (discussed in Sect. 3.2). By selecting realistic thicknesses of snow and sea ice, a comparison of the impact of mineral dust on different types of snow and sea ice was performed.

In a third step, a surface layer of $1 \mathrm{~cm}$ of snow or sea ice containing $100 \mathrm{ng} \mathrm{g}^{-1}$ of Asian dust was placed on the surface of each snow and sea ice type. The underlying snow or sea ice was modelled as a clean medium containing no black carbon or mineral aerosol deposits. The thickness of this top layer was increased to $10 \mathrm{~cm}$ in $1 \mathrm{~cm}$ steps. The variation in

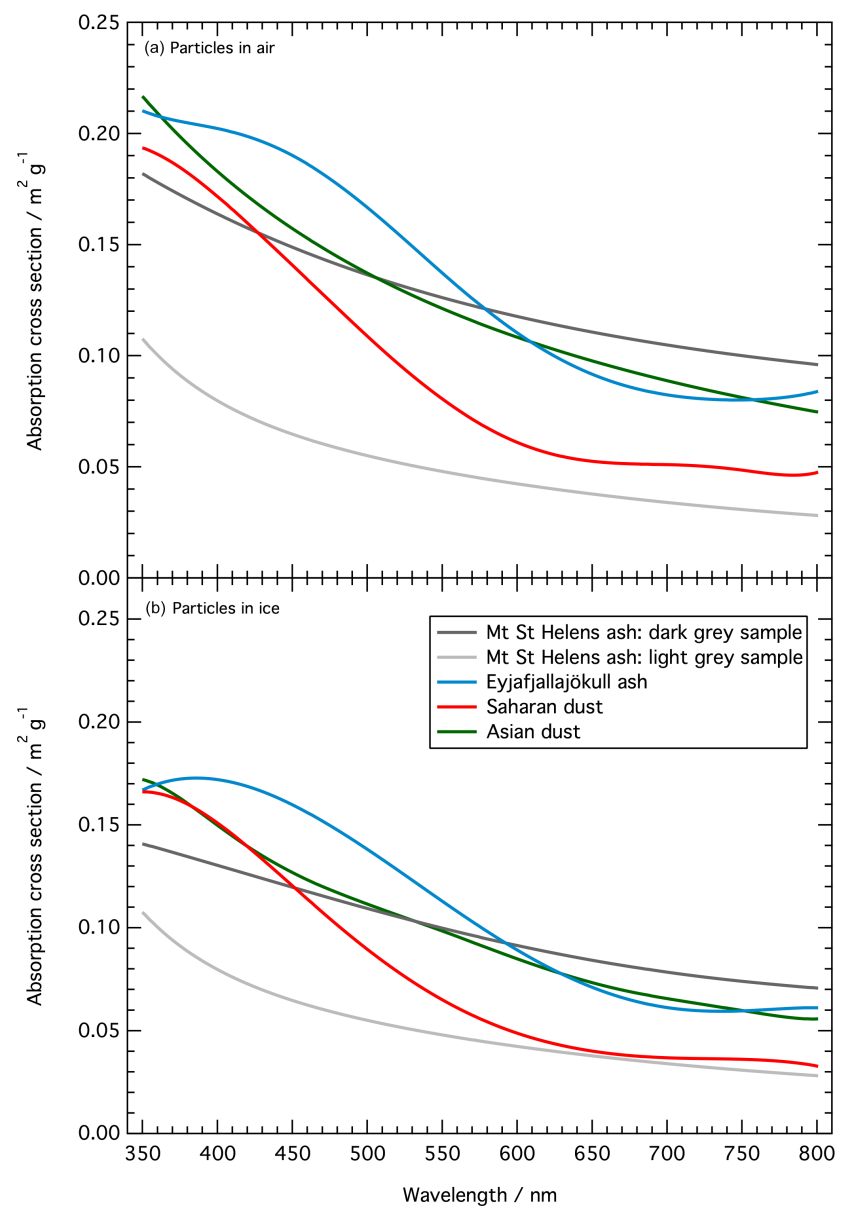

Figure 2. Absorption cross-section values based on Mie theory calculations undertaken here. Particles were considered to be surrounded by air at a temperature of $0{ }^{\circ} \mathrm{C}$ (a) for snow; and surrounded by ice (b), using refractive index data for ice from Warren and Brandt (2008) for sea ice. The size distribution of the particles used in the Mie calculation was fixed to a log normal distribution peaking at $2.3 \mu \mathrm{m}$ with a standard deviation of $2.1 \mu \mathrm{m}$. The data were smoothed with a polynomial fit to remove the fine wavelength structure.

albedo was represented as a percentage of change relative to a pure medium at four different wavelengths $(450,550,650$ and $750 \mathrm{~nm}$ ). The effects of multiple layers in snow were taken into account, simulating dust deposition by multiple storm events between snow falls. For three different $40 \mathrm{~cm}$ deep snowpacks, $100 \mathrm{ng} \mathrm{g}^{-1}$ of mineral deposits previously placed throughout the pack were concentrated to $5 \mathrm{~cm}$ layers of $800 \mathrm{ng} \mathrm{g}^{-1}$. The distance between the five layers was increased from 1 to $8 \mathrm{~cm}$ with a $1 \mathrm{~cm}$ interval in eight different model combinations, alternating poisoned and clean snow. The albedo of the layered snow packs was compared to a clean snow pack containing $1 \mathrm{ngg}^{-1}$ of mineral dust. Furthermore, the importance of buried layers containing mineral aerosol deposits was investigated by comparing multiple layers each with a dust mass ratio of $800 \mathrm{ngg}^{-1}$ to 
Case 1:

Semi-infinite

snow and sea ice

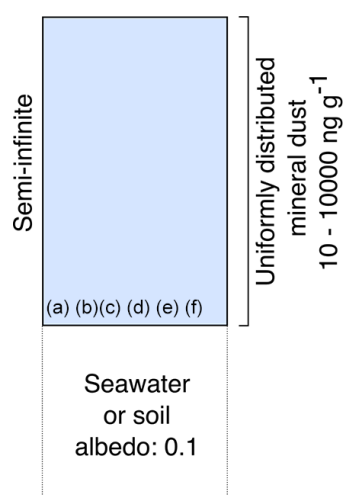

Case 2:

Realistic thicknesses

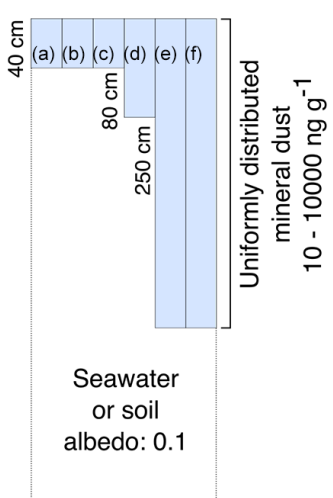

Case 3:

Layers

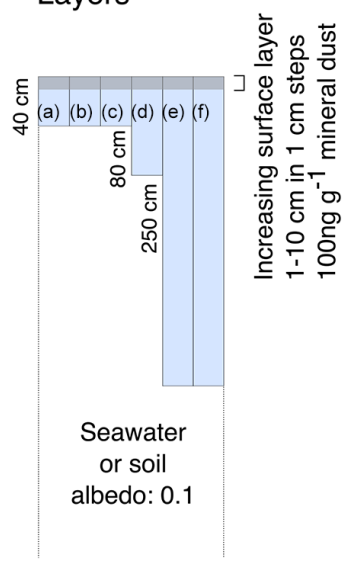

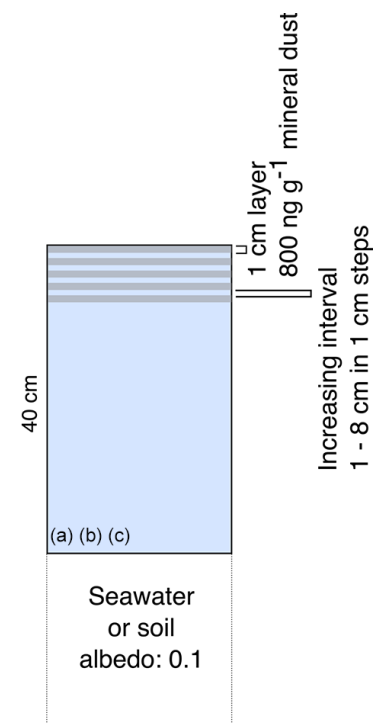

Figure 3. Snow and sea ice configurations modelled for (a) cold polar snow, (b) coastal windpacked snow, (c) melting snow, (d) first-year sea ice, (e) multi-year sea ice, (f) melting sea ice (not to scale).

one surface layer of $1 \mathrm{~cm}$ containing the same mass ratio of $800 \mathrm{ng} \mathrm{g}^{-1}$. Although typical mass ratios are lower in polar regions (Zdanowicz et al., 1998), Dong et al. (2013) show values higher than $800 \mathrm{ng} \mathrm{g}^{-1}$ in snowpacks close to dust sources. The mass ratio of $800 \mathrm{ng} \mathrm{g}^{-1}$ was selected to provide a clear signal whilst remaining realistic.

Finally, the albedo of three semi-infinite snow types (cold polar snow, coastal wind packed snow and melting snow) with an increasing mass ratio of Asian dust and light coloured Mt St Helens volcanic ash, obtained from the TUV-snow model was compared to the SNICAR-online model (Flanner et al., 2007) for validation. Identical input parameters were used for snowpack thickness, density and the underlying ground albedo. The snow grain radius parameter was varied in SNICAR-online to fit three types of clean snowpacks to the output of TUV-snow. A snow grain radius of $85 \mu \mathrm{m}$ was compared to the cold polar snow modelled in this study, $220 \mu \mathrm{m}$ for coastal wind packed snow and $1400 \mu \mathrm{m}$ for melting snow. In a second step, increasing concentrations of dust and volcanic ash were added to SNICAR-online, and the results were compared with TUV-snow.

\section{Results}

The results are presented in three sections: the effect of different types of mineral aerosol deposits on albedo of polar snow and sea ice, the variation of albedo with increasing loading of mineral aerosol deposits and the effect of layers of mineral aerosol deposits in snow.

\subsection{The effect of different mineral aerosol deposit types on albedo}

The absorption cross-sections of the different mineral aerosol deposits have a similar pattern with wavelength, but differ by a maximum of $77 \%$, as seen in Fig. 2, where the wavelengthdependant absorption cross-sections of different mineral aerosol deposits are plotted. The variation in the values of absorption cross-section has little effect on the albedo for most snow or ice types. As Fig. 4 indicates, variation in albedo between the different mineral dusts and volcanic ashes does not exceed 0.0080 for snow and 0.0788 for sea ice. For semiinfinite snow or sea ice with a mass ratio of $100 \mathrm{ngg}^{-1}$, the variation in albedo between the strongly light-absorbing Eyjafjallajökull ash and the less light-absorbing Mt. St. Helens light grey ash sample is 0.0024 for cold polar snow at $450 \mathrm{~nm}$; a wavelength where the difference between mineral deposits is the largest. For comparison, the difference in albedo at $450 \mathrm{~nm}$ between a cold polar snowpack containing $1 \mathrm{ng} \mathrm{g}^{-1}$ of Mt. St. Helens light grey ash and $100 \mathrm{ng} \mathrm{g}^{-1}$ of the same ash is 0.0036. Different mineral aerosol deposits have a larger effect on melting sea ice, where the difference in albedo between Eyjafjallajökull ash and Mt. St. Helens light grey ash reaches 0.0749 at $450 \mathrm{~nm}$. When increasing the mass ratio of mineral aerosol deposits to larger values in the snow or sea ice, the importance of their optical properties becomes more obvious. The variation in albedo between $10000 \mathrm{ng} \mathrm{g}^{-1}$ of Eyjafjallajökull ash and Mt. St. Helens light grey ash reaches 0.0268 in cold polar snow (smallest change) and 0.1444 in first-year sea ice (largest change) as shown in Fig. 5, where the albedo of different snow and sea ice types is shown for an increasing mass ratio of mineral aerosol deposits. 

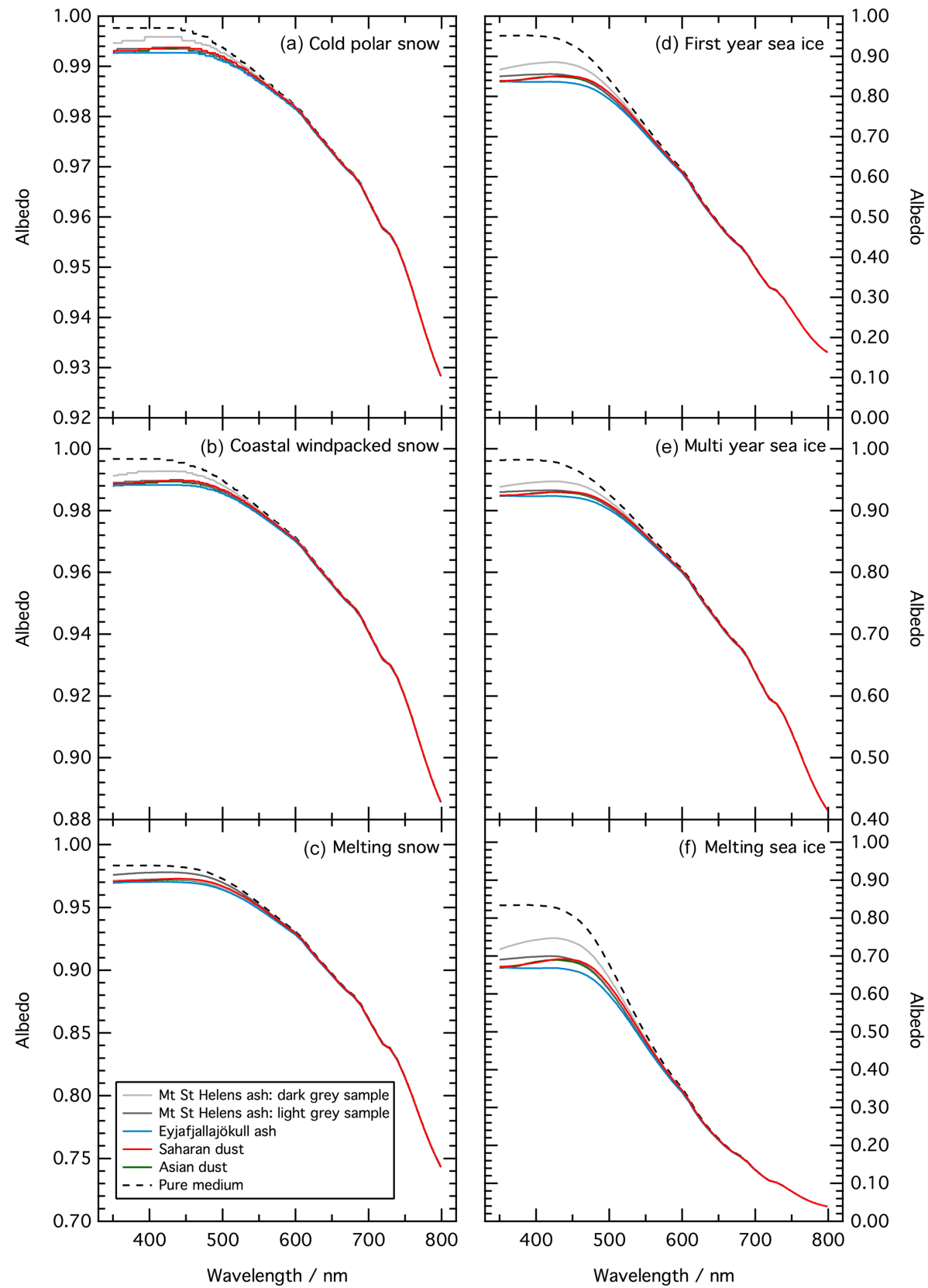

Figure 4. Wavelength-dependant albedo of three semi-infinite snow and sea ice types containing $100 \mathrm{ng} \mathrm{g}^{-1}$ of different mineral aerosol

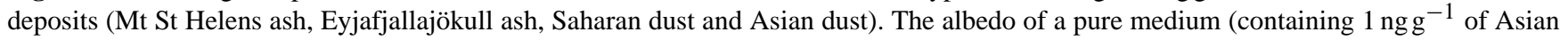
dust) has been included for comparison. The $y$ axis has different scales in each panel to cover the large range of values.

The variation in the albedo of snow and sea ice is less sensitive to the type of mineral aerosol deposit and its optical properties than to the properties of the snow or sea ice themselves (Figs. 4 and 5). Indeed, where a maximum variation of 0.0788 is observed from one mineral deposit to another, the variation between the albedo of melting sea ice and cold polar snow for the same mass ratio of mineral dust reaches 0.8893. Thus, an important result of this work is that when considering the darkening of snow or sea ice, it may be more important to understand the optical properties of the snow or sea ice than the optical properties of the mineral aerosol deposits. Therefore, when observing the impact of an increasing mineral dust mass ratio on realistic thicknesses (Fig. 7), of surface layers (Fig. 9) and of multiple layers (Fig. 10) a single type of mineral deposit was picked. Asian dust was selected, being the most commonly found mineral dust in the Arctic (Zdanowicz et al., 1998; VanCuren et al., 2012) but 

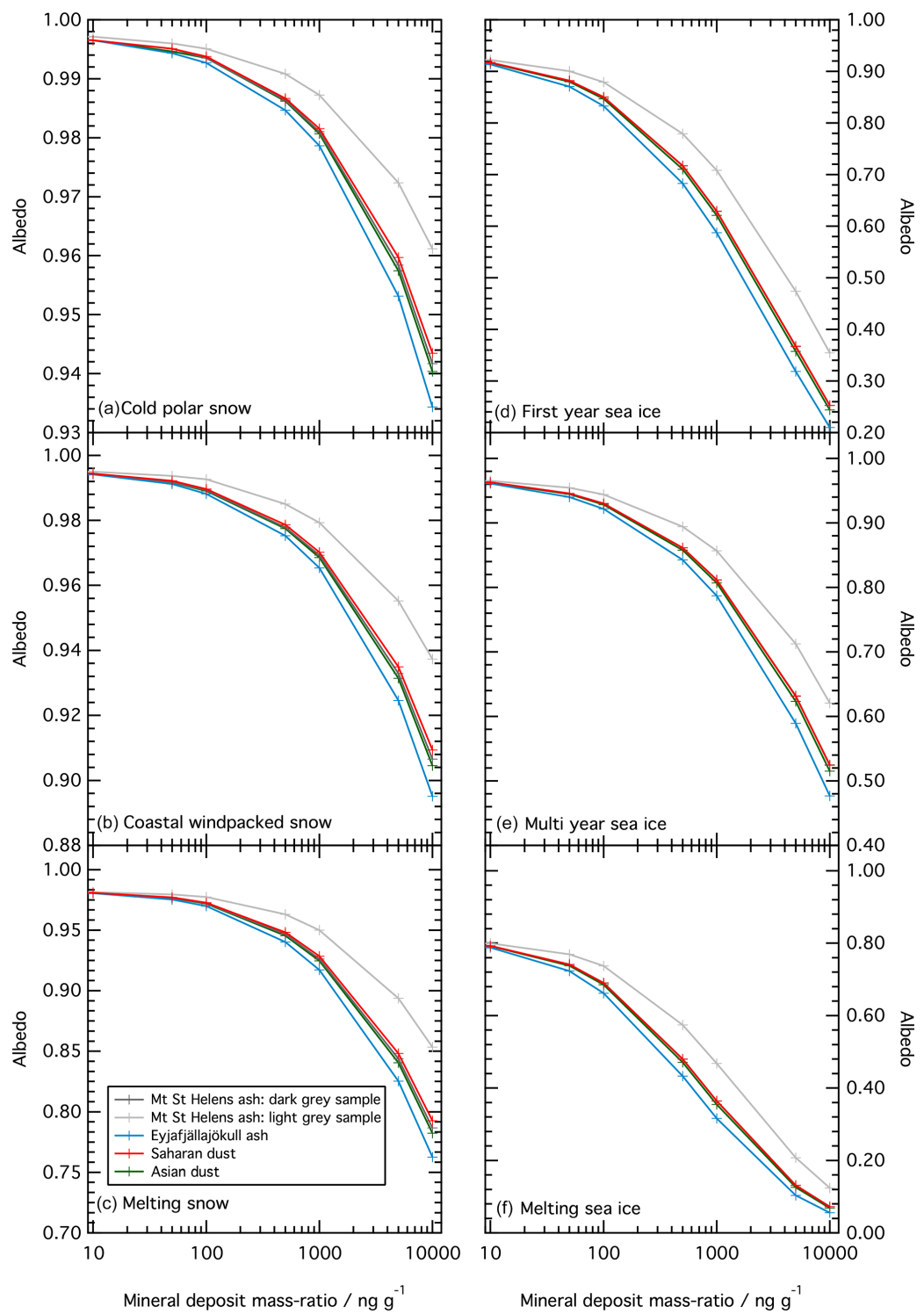

Figure 5. Albedo of three semi-infinite snow and sea ice types with increasing mineral aerosol deposits mass ratio at $450 \mathrm{~nm}$. The $y$ axis has different scales in each section to cover the large range of values.

also being representative of the range of mineral aerosol deposits (Figs. 1 and 2).

\subsection{The effects of increasing mineral dust mass ratios in snow and sea ice on albedo}

Figure 6 shows the change in albedo at $550 \mathrm{~nm}$ of an increasing mass ratio of the two most common types of mineral dust found in the Arctic for three different types of sea ice (firstyear, multi-year and melting sea ice) and snow (cold polar, coastal windpacked and melting snow) relative to a clean medium. The results presented here, as well as for Figs. 6, 5 and 7 are for a wavelength of $550 \mathrm{~nm}$, but are representative of the behaviour for a wavelength range between 400 and $600 \mathrm{~nm}$. The change in albedo shown in Figs. 6 and 9 is calculated as the ratio between the albedo of snow or sea ice containing mineral aerosol deposits and albedo calculated with a snow or sea ice containing mineral aerosol deposits at a mass ratio of $1 \mathrm{ngg}^{-1}$. Similarly to black carbon (Marks and King, 2014), mineral dust deposits have a larger impact on the albedo of sea ice than snow, with melting sea ice being the most sensitive medium. The relative change in albedo as a function of mineral dust is $87 \%$ larger for melting sea ice than a cold polar snowpack for mass ratio of $10000 \mathrm{ng} \mathrm{g}^{-1}$ of mineral dust (Fig. 6). However, such mass ratios of dust are rare in polar regions (Lawrence and Neff, 2009). Such large mass ratios are included here to allow for a wide range of applications (i.e. study areas close to aerosol sources, astrobiology and general cases). A realistic loading is below 

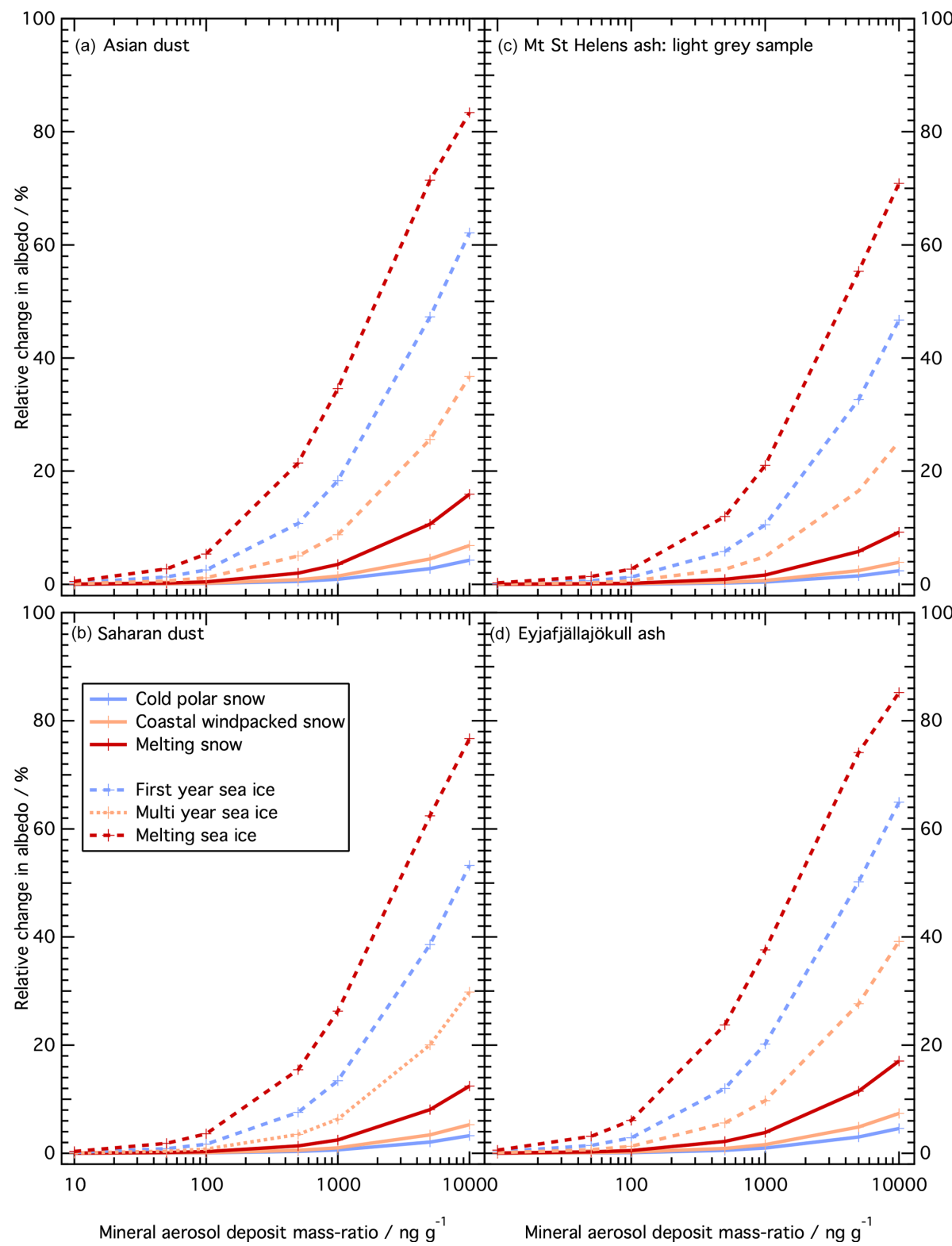

Figure 6. Relative change in albedo at a wavelength of $550 \mathrm{~nm}$ for an increasing mass ratio of (a) Asian mineral dust (b) Saharan mineral dust (c) Mt. St. Helens volcanic ash (d) Eyjafjällajökull volcanic ash relative to a mass ratio of $1 \mathrm{ng} \mathrm{g}^{-1}$ throughout three semi-infinite snow and sea ice types. The albedo for $1 \mathrm{ng} \mathrm{g}^{-1}$ of mineral aerosol deposits, valid for (a), (b), (c) and (d), is 0.988 for cold polar snow, 0.981 for coastal windpacked snow, 0.953 for melting snow, 0.727 for first-year sea ice, 0.867 for multi-year sea ice and 0.494 for melting sea ice. The values presented for a wavelength of $550 \mathrm{~nm}$ are indicative of the same behaviour for wavelengths between 400 and $600 \mathrm{~nm}$.

a mass ratio of $100 \mathrm{ngg}^{-1}$ (Zdanowicz et al., 1998), where mineral aerosol deposits only change albedo by up to 0.03 . The decrease of the albedo of melting sea ice with $100 \mathrm{ng} \mathrm{g}^{-1}$ of Asian dust relative to $1 \mathrm{ng} \mathrm{g}^{-1}$ is $5.35 \%$ and only $0.12 \%$ for cold polar snow. For smaller mass ratios, the effects of mineral aerosol deposits are negligible in snow and small in sea ice: $10 \mathrm{ng} \mathrm{g}^{-1}$ of Asian dust decreases the albedo of cold polar snow by $0.002 \%$ and melting sea ice by $0.52 \%$ relative to a mass ratio of $1 \mathrm{ngg}^{-1}$.
Figure 7 displays decreasing albedo with increasing mass loading of Asian mineral dust at a wavelength of $550 \mathrm{~nm}$ with realistic thicknesses of snow and sea ice (Table 1). The realistic thickness of snow and sea ice prevents the snow and sea ice types (except multi-year sea ice) from being optically thick. Using realistic values, the absorbing medium under the snowpack or sea ice affects the value of surface albedo. Table 1 highlights typical values for the different snow or sea ice types along with their $e$-folding depths. The snow and sea ice packs were considered to become optically thick at $3 e$ - 


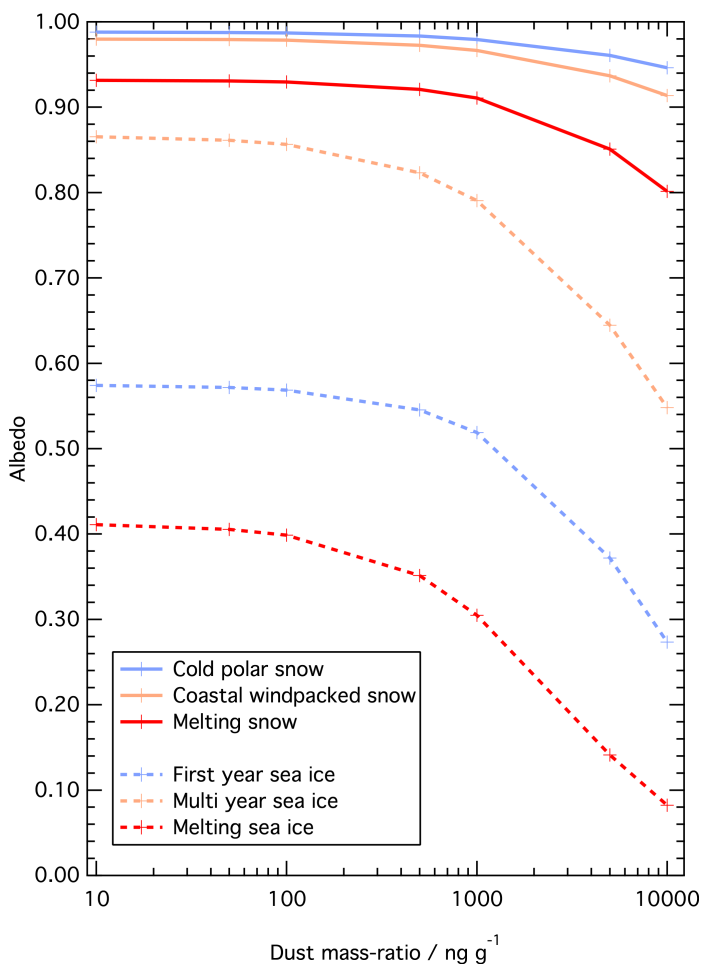

Figure 7. Albedo of three snow and sea ice types with increasing Asian dust mass ratio at $550 \mathrm{~nm}$. Snow thickness: $40 \mathrm{~cm}$, first-year sea ice: $80 \mathrm{~cm}$, multi-year and melting sea ice: $250 \mathrm{~cm}$.

folding depths, where over $95 \%$ of incident sunlight is attenuated (France et al., 2011b). The decrease in albedo between a clean snow or sea ice and a snow or sea ice containing the same loading of Asian dust is smaller for realistic depths than for semi-infinite packs. With a concentration of $100 \mathrm{ng} \mathrm{g}^{-1}$ of Asian dust, the variation is smaller by a factor of $\sim 0.97$ for a realistic thickness than a semi-infinite cold polar snowpack, $\sim 1.18$ for coastal wind packed snow, $\sim 1.91$ for melting snow, $\sim 3.05$ for first-year sea ice, $\sim 1.02$ for multi-year sea ice and $\sim 1.97$ for melting sea ice. The strong absorbing layer under the snow or sea ice (albedo of 0.1) and a thickness smaller than the minimal optical thickness for the realistic snow and sea ice layers explain a reduction in albedo and smaller variations due to mineral aerosol deposits. Figure 7 also highlights the difference in albedo decrease between realistic snow and sea ice with the same mass ratio and category of mineral aerosol deposit. Within the snow, reduction in albedo is greater for melting snow, where $1000 \mathrm{ng} \mathrm{g}^{-1}$ of mineral aerosol deposits causes a $2.25 \%$ decrease relative to a clean snow pack, than for cold polar snow, where the same loading causes a $0.89 \%$ decrease. Moreover, warmer sea ice is more sensitive than cold first-year sea ice, as a mass ratio of $1000 \mathrm{ng} \mathrm{g}^{-1}$ of mineral aerosol deposits causes a $26.05 \%$ reduction in albedo relative to clean ice for melting sea ice and $9.71 \%$ for first-year sea ice. The results presented in this section suggest that the type of snow or sea ice are more im-

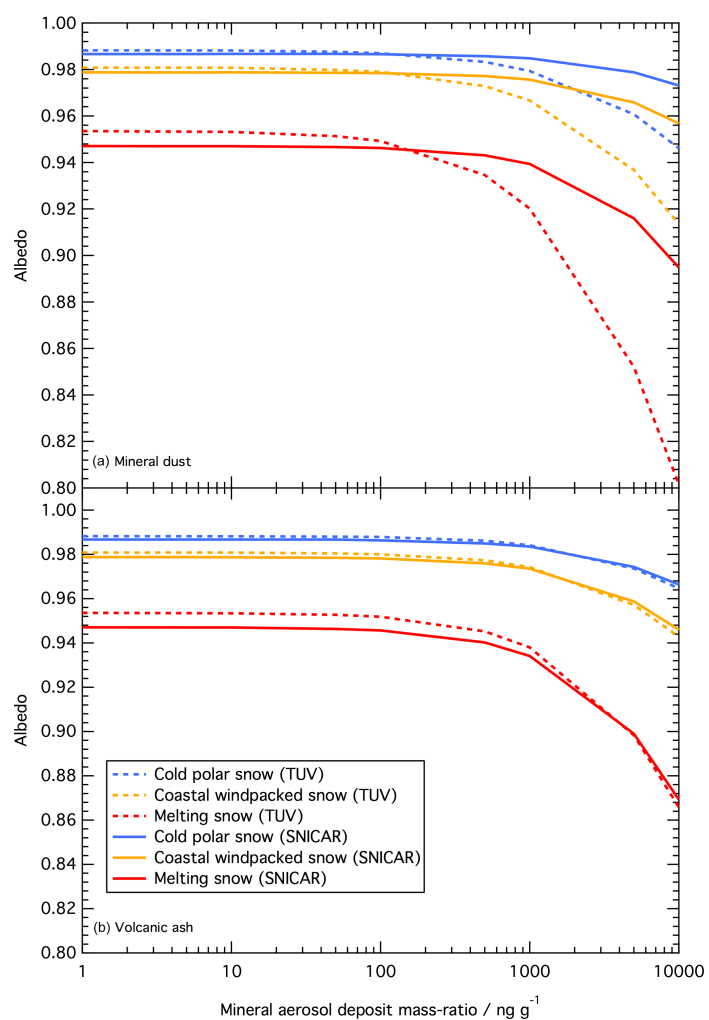

Figure 8. Comparison between the albedo of three semi-infinite snow types with an increasing mass ratio of mineral aerosol deposits computed with TUV-snow and SNICAR-online models. The dotted lines show albedo as a function of an increasing mass ratio of Asian dust (a) and a light coloured sample of Mt St Helens volcanic ash (b). The solid lines show the output from the SNICAR-Online model (Flanner et al., 2007) using input parameters matching TUV.

portant to consider than the type of mineral aerosol deposits when studying the impact of atmospheric mineral aerosol deposition on the albedo of snow and sea ice.

When comparing the results from the modelling in this study with the output from SNICAR-online (Flanner et al., 2007), a very good agreement for the albedo of an increasing mass ratio of volcanic ash can be observed (Fig. 8). The mean difference between the models ( 350 to $800 \mathrm{~nm}$ ) is 0.0013 for cold polar snow, 0.0019 for coastal wind packed snow and 0.0050 for melting snow. With mineral dust, the models present a good agreement until $100 \mathrm{ng} \mathrm{g}^{-1}$. For larger mass ratios, TUV-snow predicts a significantly lower albedo than SNICAR-online. The mean difference between the models when comparing mineral dusts is 0.0065 for cold polar snow, 0.010 for coastal wind packed snow and 0.023 for melting snow.

\subsection{The effect of mineral dust layers in snow and sea ice}

Owing to the episodic nature of dust storms and volcanic eruptions, mineral aerosol deposits can occur in snow and sea 


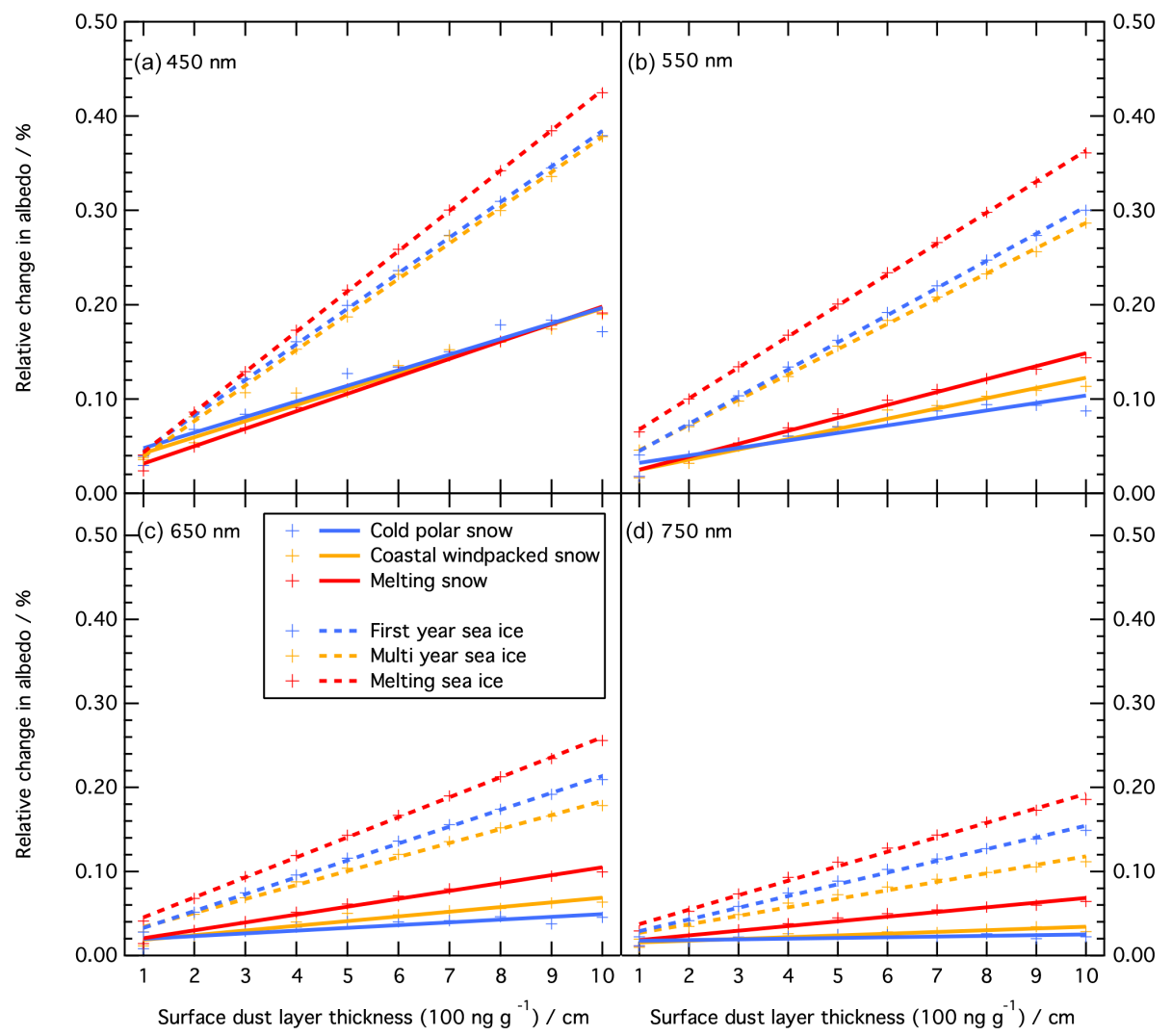

Figure 9. Relative change in albedo for an increasing surface layer of $100 \mathrm{ng} \mathrm{g}^{-1}$ of mineral dust between $1 \mathrm{~cm}$ and $10 \mathrm{~cm}$ at 450 (a), 550 (b), 650 (c) and $750 \mathrm{~nm}$ (d). The albedo without a surface layer is 0.996 at $450 \mathrm{~nm}, 0.988$ at $550 \mathrm{~nm}, 0.973$ at $650 \mathrm{~nm}$ and 0.950 at $750 \mathrm{~nm}$ for cold polar snow, 0.989 at $450 \mathrm{~nm}, 0.980$ at $550 \mathrm{~nm}, 0.957$ at $650 \mathrm{~nm}$ and 0.920 at $750 \mathrm{~nm}$ for coastal windpacked snow, 0.943 at $450 \mathrm{~nm}$, 0.932 at $550 \mathrm{~nm}, 0.892$ at $650 \mathrm{~nm}$ and 0.815 at $750 \mathrm{~nm}$ for melting snow, 0.611 at $450 \mathrm{~nm}, 0.575$ at $550 \mathrm{~nm}, 0.452$ at $650 \mathrm{~nm}$ and 0.267 at $750 \mathrm{~nm}$ for first-year sea ice, 0.950 at $450 \mathrm{~nm}, 0.866$ at $550 \mathrm{~nm}, 0.721$ at $650 \mathrm{~nm}$ and 0.542 at $750 \mathrm{~nm}$ for multi-year sea ice and 0.505 at $450 \mathrm{~nm}, 0.412$ at $550 \mathrm{~nm}, 0.215$ at $650 \mathrm{~nm}$ and 0.079 at $750 \mathrm{~nm}$ for melting sea ice.

ice as layers resulting from these events. The previous calculations were repeated, confining the mineral aerosol deposits to a surface layer with a thickness varying from 1 to $10 \mathrm{~cm}$, then to a series of five layers of $1 \mathrm{~cm}$ with a spacing varying from 1 to $8 \mathrm{~cm}$. Figure 9 demonstrates the relative change in albedo for an increasing mass ratio of Asian dust in an increasing surface layer in snow and sea ice. The change in albedo is small: $10 \mathrm{~cm}$ of $100 \mathrm{ng} \mathrm{g}^{-1}$ of dust on melting sea ice induces a change of $0.47 \%$ at $450 \mathrm{~nm}, 0.36 \%$ at $550 \mathrm{~nm}$, $0.26 \%$ at $650 \mathrm{~nm}$ and $0.19 \%$ at $750 \mathrm{~nm}$ relative to a clean sea ice. Although the mass ratio of mineral dust observed in the Arctic is much larger than black carbon, the impact of the former on snow and sea ice is less important. Marks and King (2014) show that a surface layer of $5 \mathrm{~cm}$ of evenly distributed black carbon with a mass ratio of $100 \mathrm{ng} \mathrm{g}^{-1}$ causes a reduction of albedo of $1.3 \%$ at $450 \mathrm{~nm}$ for first-year sea ice. The same layer, containing $100 \mathrm{ng} \mathrm{g}^{-1}$ of Asian dust only reduces albedo by $0.21 \%$ at $450 \mathrm{~nm}$ (Fig. 9).

Figure 10 shows the effect of multiple layers evenly buried

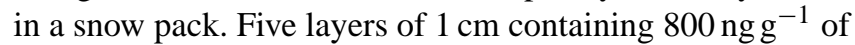
Asian dust were placed in different $40 \mathrm{~cm}$ thick snow packs (polar, coastal wind packed and melting snow). The distance between the layers was increased evenly from 1 to $8 \mathrm{~cm}$. Surface albedo was compared with a single $1 \mathrm{~cm}$ surface layer containing $800 \mathrm{ng} \mathrm{g}^{-1}$ of Asian dust and a clean snow pack. Figure 10 shows that multiple layers of mineral dust play an important part in the reduction of albedo, even when placed wide apart in the snowpack. Indeed, $1 \mathrm{~cm}$ layers containing mineral dust placed $8 \mathrm{~cm}$ apart continue to reduce albedo without the overlying snow reducing the contribution to zero. When comparing the results from Figs. 10 and 7, the difference in albedo between a uniform $40 \mathrm{~cm}$ snowpack containing $100 \mathrm{ng} \mathrm{g}^{-1}$ of Asian dust and the same mass of dust concentrated into five layers of $800 \mathrm{ng} \mathrm{g}^{-1}$ with a $1 \mathrm{~cm}$ interval is small: 0.0025 for polar snow and 0.0031 for coastal wind packed and melting snow at $550 \mathrm{~nm}$. A snowpack containing multiple layers of more concentrated dust with a small spacing is thus likely to cause a similar reduction in albedo at shorter wavelengths than a snowpack where the dust is uniformly distributed.

As seen in the previous results, the effects of mineral dust are more important at shorter wavelengths than in the near 

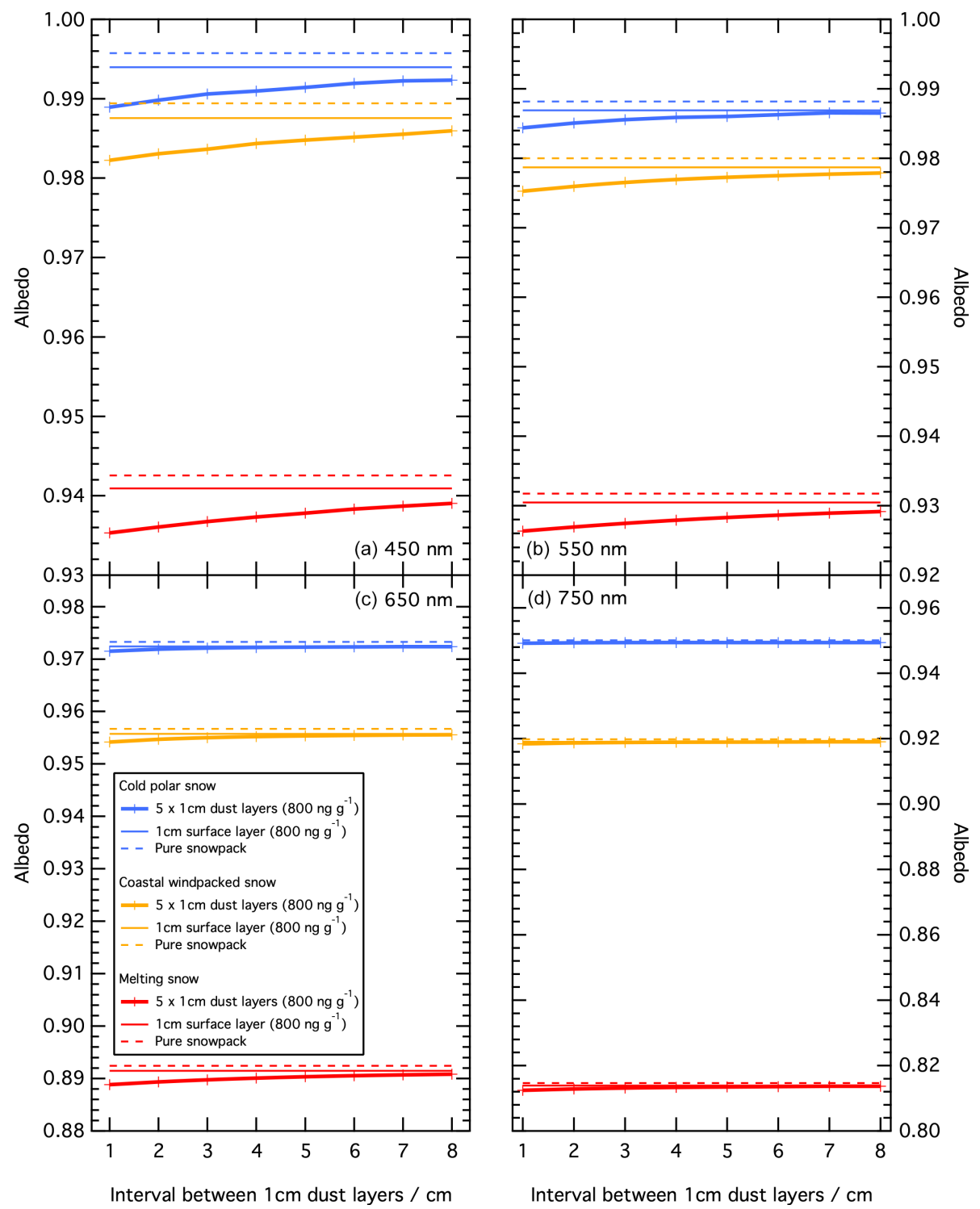

Figure 10. Albedo of three snow types ( $40 \mathrm{~cm}$ thick) containing five layers of $800 \mathrm{ng} \mathrm{g}^{-1}$ dust with varying intervals from 1 to $8 \mathrm{~cm}$. The dotted line represents a pure snowpack containing a dust mass ratio of $1 \mathrm{ng} \mathrm{g}^{-1}$ of Asian dust. The thin line represents a pure snowpack with a $1 \mathrm{~cm}$ thick surface layer containing $800 \mathrm{ng} \mathrm{g}^{-1}$ of Asian dust. The thick line and markers represent a pure snowpack with 5 layers each containing $800 \mathrm{ng} \mathrm{g}^{-1}$ of Asian dust. The $x$ axis shows the spacing between the 5 layers, varying between 1 and $8 \mathrm{~cm}$.

infrared. At $550 \mathrm{~nm}$, five layers at $1 \mathrm{~cm}$ interval containing $800 \mathrm{ng} \mathrm{g}^{-1}$ of mineral dust in cold polar snow cause a reduction in albedo of $0.68 \%$ relative to a clean snow pack against only $0.10 \%$ at $750 \mathrm{~nm}$.

\section{Discussion}

The following discussion provides explanations of the results presented in Sect. 3 and a discussion on the limitations of this study.

\subsection{Model uncertainties}

\subsubsection{Mie calculation}

The composition of light-absorbing impurities in polar snow and sea ice has been well characterised (e.g. Flanner et al., 2012; Kumai, 1977; Thompson, 1977; Warren, 1982; Zdanowicz et al., 1998). However, values of the optical properties of dust and volcanic ash aerosols remain scarce. Work has been carried out to measure the phase function (e.g. Dubovik et al., 2002a) scattering matrices (Muñoz, 2004) and brightness temperature (Newman et al., 2012) of mineral aerosols, but, to the knowledge of the authors of this 
paper, comprehensive results of wavelength-dependant complex refractive index measurements other than the data presented in this paper are lacking. When presented, refractive index data generally refer to mineral equivalents or weighted combinations of mineral values (Flanner et al., 2007; Derimian et al., 2012). Consequently, the study was limited to a reduced number of sources when choosing appropriate mineral aerosol optical properties presented here as model input parameters. However, variation between the type of mineral aerosol deposits has a limited impact on albedo relative to the effect of variation in the type of snow and sea ice, as discussed in Sect. 4.2. An array of mineral dusts and ashes was selected from plausible geographical sources contributing to the Arctic at present (Pacyna and Ottar, 1989; Zdanowicz et al., 1998; Bory, 2003; VanCuren et al., 2012). More importantly, the selection covers a range of complex refractive indices that can be applied to different study areas. The absorption cross-sections of the selection of mineral aerosols used in this study vary by a factor of $\sim 2$, allowing the model to be adapted to different areas affected by different types of dust.

In order to calculate the absorption spectrum of the mineral aerosol deposits, Mie scattering theory was used, assuming that the particles were spheres. Dust particles are known to be non-spherical, thus affecting differently the light scattering properties (Mishchenko et al., 1995, 1999; Dubovik et al., 2002b). Studies have focused on non-spherical particles in Mie theory (e.g. Purcell and Pennypacker, 1973), but due to the complexity of the interaction of light with multiple shapes, its modelling is very challenging (Nousiainen, 2009), and approximations have to be made. However, it is possible to calculate a relative change in absorption cross-section if a spherical Mie scattering particle is morphed into a needle or a disk. Bohren and Huffman (1983) proposed three equations for extreme forms of ellipsoids (spheres, needles and disks) allowing for the representation of the shapes found in mineral aerosols. Needles may correspond to glass shards found in volcanic ash (Johnson et al., 2012), and dust particles take on a variety of shapes amongst which flat disks can be observed (Mishra and Tripathi, 2008). At $550 \mathrm{~nm}$ the absorption cross-section for the volcanic ash may increase by a factor of $\sim 1.20$ for needles and $\sim 1.53$ for disks. The absorption cross-section for the dusts may increase by a factor of $\sim 1.21$ for needles and $\sim 1.56$ for disks. Whilst the shape of needles, disks and spheres is probably too limited to describe mineral particles, consideration of the particle morphology allows the magnitude of the effect of morphology to be estimated. The calculation is dependant on the refractive index of particles but the change in shape would be expected to cause a larger change to the absorption cross-section than the small difference in refractive index between the particles. The effect being multiplicative, the percentage of change in values can be applied to the mass ratio values in the relative change in albedo (see Figs. 6 and 7) to correct for shape effects. The variations related to particle shape were not con- sidered in this study, but a typical uncertainty is a factor of $\sim 1.5$.

Whilst calculating the absorption cross section of mineral aerosol deposits using Mie theory, assumptions had to be made to include the impurities in the snow or sea ice. The particles can be considered either in or on the snow grains constituting the snowpack, and in sea ice, the particles can either be located in the ice or in the brine (Chýlek et al., 1983). The refractive index of air was used as a surrounding medium for particles in snow, considering that the impurities are external to the snow. In the case of sea ice, the values of pure ice from Warren and Brandt (2008) were used. The distribution of mineral contaminants in sea ice varies with depth and temperature, making it difficult to characterise their surrounding medium. After comparing cross-section absorption values of dust in brine (Maykut and Light, 1995) and in pure ice, the difference was considered to be negligible, with a relative change of $0.1 \%$ between the two.

\subsubsection{Snowpack or sea ice thickness}

When modelling the albedo of semi-infinite and realistic thicknesses of snow and sea ice, the mineral dust was assumed to be uniformly distributed throughout the snow and sea ice. Such an assumption does not account for the layering effect observed in field measurements, but represents a mean value, easily applicable to a vast spatial extent. Layering effects were studied in Sect. 3.3 by looking at a surface layer and multiple buried layers. Although the configurations used here do not cover all the possibilities found in the field, this study presents an overview of an effect previously unquantified and can be adapted to particular scenarios.

Snow or sea ice thickness is an essential parameter in the calculation of albedo. It is also difficult to quantify, due to temporal and spatial heterogeneity. Sea ice has varying surface conditions, associated with depths ranging from 0 to over $10 \mathrm{~m}$ at pressure ridges (Perovich, 1996). A detailed study would require individual cases with different layers of sea ice and associated thicknesses. Where snow is typically sufficiently optically thick to produce general results, this is not the case for sea ice. Therefore, a range of sea ice types (first-year sea ice, multi-year sea ice and melting sea ice) and their associated depths was produced in this study. To calculate the relative change in albedo with an increasing mass ratio of mineral aerosol deposits (Fig. 6) and the effects of different types of mineral dusts and volcanic ashes (Fig. 4), thickness values large enough to guarantee a semiinfinite medium were used, allowing for the fair comparison of the effects of mineral aerosol deposits on the albedo of each type of snow and sea ice. When accounting for realistic thicknesses in Fig. 7, typical depths found in the literature were picked. The selection of depths used in this study are considered to be representative and the results can be calculated for any given thickness using the method presented in Sect. 2. 
The modelling presented here has several limitations. In this study, the combination of different types of absorbing impurities that can be found in the Arctic, such as soot, HULIS, or black carbon (Marks and King, 2013; Warren and Clarke, 1990) was not considered. However, Marks and King (2014) have modelled the effects of black carbon in similar types of snow and sea ice to the ones used here and the effects of soot have been considered by Warren and Clarke (1990). Organic debris and algae, that have an effect on albedo (Grenfell, 1991) and may have been observed in field data (France et al., 2012), were not examined in this study. Indeed, light-absorbing impurities other than the mineral aerosol deposits described in Sect. 2.2 were not considered. In the case of studies considering multiple light-absorbing impurities in the snow or sea ice, France et al. (2012) demonstrated how to separate the effects of different light-absorbing impurities from black carbon for snow on sea ice.

\subsubsection{Asymmetry parameter}

The asymmetry parameter, $g$, was one of the parameters used to describe the snow and sea ice. A fixed value of 0.95 for sea ice and 0.89 for snow were determined, based on the values presented by France et al. (2012) and Marks and King (2013). In the two papers, $g$ was held constant and $\sigma_{\text {scatt }}$ and $\sigma_{\text {abs }}^{+}$ varied, based on the methods of Lee Taylor and Madronich (2002). Libois et al. (2014) advocate the use of a value of $g=0.86$ when modelling snow. To gauge the effects of the value of $g$ on albedo, the scattering and absorption coefficients of the cold polar snow and the melting snow were recalculated from albedo and $e$-folding depth data, using the optical properties in Table 1. The calculations for the effects of Saharan dust were then repeated with the value of $g$ recommended by Libois et al. (2014). The difference in albedo between $g=0.89$ and $g=0.86$ was of $0.006 \%$ for a cold polar snowpack containing $10 \mathrm{ng} \mathrm{g}^{-1}$ of Saharan dust, $0.009 \%$ for $100 \mathrm{ng} \mathrm{g}^{-1}$ and $0.18 \%$ for $10000 \mathrm{ng} \mathrm{g}^{-1}$ and $0.01 \%$ for a melting snowpack containing $10 \mathrm{ng} \mathrm{g}^{-1}$ of Saharan dust, $0.02 \%$ for $100 \mathrm{ng} \mathrm{g}^{-1}$ and $0.93 \%$ for $10000 \mathrm{ng} \mathrm{g}^{-1}$. Therefore, the results presented in this study have been produced without updating the asymmetry parameter $g$.

\subsection{Effect of mineral aerosol deposits on snow and sea ice}

Much larger mass ratios of mineral aerosol deposits are necessary to induce a change in albedo, in comparison with black carbon or soot. In a similar modelling study, Marks and King (2014) found that for a wavelength of $550 \mathrm{~nm}$, $10 \mathrm{ng} \mathrm{g}^{-1}$ of black carbon evenly distributed throughout semi-infinite sea ice causes a $22.9 \%$ change in albedo relative to a clean medium for first-year sea ice, $11.2 \%$ for multiyear sea ice and $37.6 \%$ for melting sea ice. To achieve the same change, a mass ratio between 1083 and $1197 \mathrm{ng} \mathrm{g}^{-1}$ of Asian dust would be necessary. However, larger mass ratios of dust are found in polar snow and sea ice, with seasonal deposition events (Zdanowicz et al., 1998).

The calculations of the albedo of snow and sea ice in relation to different types of mineral aerosol deposits commonly found in the Arctic enabled the comparison between types of contaminants and between the different snow and sea ice types. The change in albedo induced by different types of snow or sea ice is greater than the type of mineral. The results obtained here show that snow and sea ice with a smaller scattering cross-section are more sensitive to the effects of mineral aerosol deposits on the albedo, confirming the work of Marks and King (2014), who quantified the phenomenon for the same snow and sea ice types.

The wavelength-dependant effects of mineral aerosol deposits on albedo are similar to black carbon. The results of this study present a good agreement with the work of Warren and Wiscombe (1980). Indeed, the absorbing aerosol deposits mainly affect shortwave radiation. In the infrared, mineral aerosol deposits barely influence the albedo of snow and sea ice, as described by Warren and Wiscombe (1980) and Carmagnola et al. (2013). The effect of mineral aerosol deposits becoming smaller at larger wavelengths can be explained by the increasing absorption by the ice that exceeds absorption by mineral aerosol deposits.

\subsection{Comparison with SNICAR-online}

The results of this modelling study were compared with the output of the SNICAR-online model. The two models are in agreement when the same mineral aerosol deposits in the snow are used. The volcanic ash in the model from Flanner et al. (2007) was derived from measurements of Mt. St. Helens eruption (Patterson, 1981), corresponding to the light grey sample of Mt. St. Helens ash used in this study. The difference in the results for mineral dust can be explained by the use of a different type of dust as input. SNICAR-online uses a combination of indices of refraction of quartz, limestone, montmorillonite, illite and hematite (Flanner et al., 2007), whereas the work presented here uses the refractive indices of real dust sources, which are more representative of the aerosols present in the atmosphere. Nevertheless, the difference in albedo for high loadings of different dusts shows the importance of the mineral aerosol type at extreme loadings. The comparison between the two models for other types of mineral aerosol deposits, sea ice or layers was not possible, as the features are not present in SNICAR-online.

In Fig. 9, the relative change in albedo with an increasing surface layer of mineral dust can be fitted with a linear regression. However, the relative change in albedo for media containing a uniform loading throughout is not linear. For small changes in albedo, the relationship between fractional change in albedo and dust mass ratio is approximately linear. Although the loading is important in the surface layer, the total amount of mineral aerosol deposit is small compared to 
a snow or ice pack with an even loading of mineral aerosol deposits.

The effect of dust layers varies significantly depending on their vertical location and distribution of the dust layers. An increasing surface layer thickness only causes a small change, as seen in Fig. 9. At visible wavelengths, the effect of multiple layers of dust distributed through the snowpack has a significant effect on the reduction of albedo. A $1 \mathrm{~cm}$ thick layer containing the same mass ratio as the individual buried layers was placed on the snow surface (Fig. 10) to compare with the role of the buried layers. Even when spaced out with $8 \mathrm{~cm}$ intervals, the buried layers caused a 0.0034 reduction in albedo at $450 \mathrm{~nm}$ for cold polar snow where a $1 \mathrm{~cm}$ surface layer caused a change in albedo of 0.0017. For comparison, the same mass evenly spread out through the snowpack causes a decrease of 0.0012 in albedo compared to a clean snowpack. Dust layers within snowpacks are typically greater than $8 \mathrm{~cm}$ (e.g. Zdanowicz et al., 1998; Osada et al., 2004; Dong et al., 2013) and inspection of Fig. 10 shows that as the distance between the layers increases, the difference between the albedo of the layered snowpack and the snowpack containing a single surface layer becomes small. Therefore as a first approximation, layer thicknesses significantly greater than $8 \mathrm{~cm}$ may be neglected.

\section{Conclusions}

The response of the albedo of snow and sea ice to mineral aerosol deposits is more sensitive to the type of snow or sea ice than to the properties of the mineral aerosol deposits themselves. Radiative-transfer calculations show that the albedo of melting sea ice is more responsive to mineral aerosol deposits than snow or first/multi-year sea ice. However, larger mass ratios of mineral aerosol deposits than what is found in nature are needed to induce a significant change in albedo, even for the more responsive melting sea ice. These higher mass ratios are more likely to be deposited by storm events on snowpacks thus forming alternating layers of polluted and pure snow. The thickness of a surface layer has surprisingly little effect on albedo, whereas multiple layers buried in snow have a larger impact than a uniform mixing throughout the snowpack. Amongst the different snow and sea ice types investigated, a melting medium is more affected by the radiative forcing of mineral aerosol deposits. The time of year associated with these snow and sea ice cover implies that solar radiation is at its strongest, creating positive feedback and accelerating the melting process further.

So far, few studies have focussed on the impact of mineral aerosol deposits, giving more importance to black carbon and soot. This study demonstrates that the effects of natural pollutants need to be taken into account when investigating albedo reduction in the Arctic. Therefore, the community studying global climate change can use Fig. 6 as an input in general circulation models with very little computational effort, further reducing uncertainties.

Acknowledgements. MDK and MLL thank NERC for support under Grant NE/K000770X/1 and NERC FSF (555.0608).

Edited by: J. Huang

\section{References}

Aoki, T., Aoki, T., Fukabori, M., Tachibana, Y., Zaizen, Y., Nishio, F., and Oishi, T.: Spectral albedo observation on the snow field at Barrow, Alaska, Polar Meteorol. Glaciol., 12, 1-9, 1998.

Balkanski, Y., Schulz, M., Claquin, T., and Guibert, S.: Reevaluation of Mineral aerosol radiative forcings suggests a better agreement with satellite and AERONET data, Atmos. Chem. Phys., 7, 81-95, doi:10.5194/acp-7-81-2007, 2007.

Barry, R. G., Serreze, M. C., Maslanik, J. A., and Preller, R. H.: The Arctic Sea Ice-Climate System: Observations and modeling, Rev. Geophys., 31, 397-422, 1993.

Bohren, C. F. and Huffman, D. R.: Absorption and Scattering of Light by Small Particles, John Wiley \& Sons, Weinheim, Germany, 1983.

Bory, A. J. M.: Two distinct seasonal Asian source regions for mineral dust deposited in Greenland (NorthGRIP), Geophys. Res. Lett., 30, 1167, doi:10.1029/2002GL016446, 2003.

Bourke, R. H. and Garrett, R. P.: Sea ice thickness distribution in the Arctic Ocean, Cold Reg. Sci. Technol., 13, 259-280, 1987.

Buckley, R. G. and Trodahl, H. J.: Thermally driven changes in the optical properties of sea ice, Cold Reg. Sci. Technol., 14, 201204, 1987.

Carmagnola, C. M., Domine, F., Dumont, M., Wright, P., Strellis, B., Bergin, M., Dibb, J., Picard, G., Libois, Q., Arnaud, L., and Morin, S.: Snow spectral albedo at Summit, Greenland: measurements and numerical simulations based on physical and chemical properties of the snowpack, The Cryosphere, 7, 1139-1160, doi:10.5194/tc-7-1139-2013, 2013.

Chýlek, P., Ramaswamy, V., and Srivastava, V.: Albedo of sootcontaminated snow, J. Geophys. Res.-Atmos., 88, 10837-10843, 1983.

Clarke, A. D. and Noone, K. J.: Soot in the Arctic snowpack: A cause for perturbations in radiative transfer, Atmos. Environ., 19, 2045-2053, 1985.

Conway, H., Gades, A., and Raymond, C. F.: Albedo of dirty snow during conditions of melt, Water Resour. Res., 32, 1713-1718, 1996.

Curry, J. A., Schramm, J. L., and Ebert, E. E.: Sea Ice-Albedo Climate Feedback Mechanism, J. Climate, 8, 240-247, 1995.

Dang, C., Brandt, R. E., and Warren, S. G.: Parameterizations for narrowband and broadband albedo of pure snow and snow containing mineral dust and black carbon, J. Geophys. Res.-Atmos., 120, 5446-5468, doi:10.1002/2014JD022646, 2015.

Derimian, Y., Dubovik, O., Tanre, D., Goloub, P., Lapyonok, T., and Mortier, A.: Optical properties and radiative forcing of the Eyjafjallajökull volcanic ash layer observed over Lille, France, in 2010, J. Geophys. Res.-Atmos., 117, D00U25, doi:10.1029/2011JD016815, 2012. 
Doherty, S. J., Warren, S. G., Grenfell, T. C., Clarke, A. D., and Brandt, R. E.: Light-absorbing impurities in Arctic snow, Atmos. Chem. Phys., 10, 11647-11680, doi:10.5194/acp-1011647-2010, 2010.

Dong, Z., Li, Z., Wang, W., Li, K., and Zhou, P.: Characteristics of atmospheric dust deposition in snow on Glacier No. 4, Mt Bogeda, China, Environ. Earth Sci., 70, 1423-1433, doi:10.1007/s12665-013-2228-z, 2013.

Dong, Z., Qin, D., Kang, S., Ren, J., Chen, J., Cui, X., Du, Z., and Qin, X.: Physicochemical characteristics and sources of atmospheric dust deposition in snow packs on the glaciers of western Qilian Mountains, China, Tellus B, 66, 20956, doi:10.3402/tellusb.v66.20956, 2014.

Dubovik, O., Holben, B., Eck, T. F., Smirnov, A., Kaufman, Y. J., King, M. D., Tanré, D., and Slutsker, I.: Variability of absorption and optical properties of key aerosol types observed in worldwide locations, J. Atmos. Sci., 59, 590-608, doi:10.1175/15200469(2002)059<0590:VOAAOP>2.0.CO;2, 2002a.

Dubovik, O., Holben, B., Lapyonok, T., Sinyuk, A., Mishchenko, M., Yang, P., and Slutsker, I.: Non-spherical aerosol retrieval method employing light scattering by spheroids, Geophys. Res. Lett., 29, 54-1-54-4, doi:10.1029/2001GL014506, 2002b.

Fischer, H., Siggaard-Andersen, M.-L., Ruth, U., Röthlisberger, R., and Wolff, E.: Glacial/interglacial changes in mineral dust and sea-salt records in polar ice cores: Sources, transport, and deposition, Rev. Geophys., 45, RG1002, doi:10.1029/2005RG000192, 2007.

Flanner, M. G., Zender, C. S., Randerson, J. T., and Rasch, P. J.: Present-day climate forcing and response from black carbon in snow, J. Geophys. Res.-Atmos., 112, D11202, doi:10.1029/2006JD008003, 2007.

Flanner, M. G., Zender, C. S., Hess, P. G., Mahowald, N. M., Painter, T. H., Ramanathan, V., and Rasch, P. J.: Springtime warming and reduced snow cover from carbonaceous particles, Atmos. Chem. Phys., 9, 2481-2497, doi:10.5194/acp-9-24812009, 2009.

Flanner, M. G., Liu, X., Zhou, C., Penner, J. E., and Jiao, C.: Enhanced solar energy absorption by internally-mixed black carbon in snow grains, Atmos. Chem. Phys., 12, 4699-4721, doi:10.5194/acp-12-4699-2012, 2012.

France, J. L., King, M. D., Frey, M. M., Erbland, J., Picard, G., Preunkert, S., MacArthur, A., and Savarino, J.: Snow optical properties at Dome C (Concordia), Antarctica; implications for snow emissions and snow chemistry of reactive nitrogen, Atmos. Chem. Phys., 11, 9787-9801, doi:10.5194/acp-11-97872011, 2011a.

France, J. L., King, M., Lee-Taylor, J., Beine, H. J., Ianniello, A., Domine, F., and MacArthur, A.: Calculations of in-snow NO2 and $\mathrm{OH}$ radical photochemical production and photolysis rates: A field and radiative-transfer study of the optical properties of Arctic (Ny-Alesund, Svalbard) snow, J. Geophys. Res., 116, F04013, doi:10.1029/2011JF002019, 2011b.

France, J. L., Reay, H. J., King, M. D., Voisin, D., Jacobi, H. W., Domine, F., Beine, H., Anastasio, C., MacArthur, A., and LeeTaylor, J.: Hydroxyl radical and NOx production rates, black carbon concentrations and light-absorbing impurities in snow from field measurements of light penetration and nadir reflectivity of onshore and offshore coastal Alaskan snow, J. Geophys. Res.Atmos., 117, D00R12, doi:10.1029/2011JD016639, 2012.
Fratini, G., Ciccioli, P., Febo, A., Forgione, A., and Valentini, R.: Size-segregated fluxes of mineral dust from a desert area of northern China by eddy covariance, Atmos. Chem. Phys., 7, 2839-2854, doi:10.5194/acp-7-2839-2007, 2007.

Ginoux, P., Garbuzov, D., and Hsu, N. C.: Identification of anthropogenic and natural dust sources using Moderate Resolution Imaging Spectroradiometer (MODIS) Deep Blue level 2 data, J. Geophys. Res.-Atmos., 115, D05204, doi:10.1029/2009JD012398, 2010.

Grenfell, T. C.: A radiative transfer model for sea ice with vertical structure variations, J. Geophys. Res.-Atmos., 96, 16991-17001, 1991.

Grenfell, T. C. and Makyut, G. A.: The optical properties of ice and snow in the Arctic Basin, J. Glaciol., 18, 445-463, 1977.

Grenfell, T. C. and Perovich, D. K.: Spectral albedos of sea ice and incident solar irradiance in the southern Beaufort Sea, J. Geophys. Res.-Atmos., 89, 3573-3580, 1984.

Grenfell, T. C., Light, B., and Sturm, M.: Spatial distribution and radiative effects of soot in the snow and sea ice during the SHEBA experiment, J. Geophys. Res.-Atmos., 107, SHE 7-1-SHE 7-7, doi:10.1029/2000JC000414, 2002.

Hanesiak, J. M., Barber, D. G., De Abreu, R. A., and Yackel, J. J.: Local and regional albedo observations of arctic first-year sea ice during melt ponding, J. Geophys. Res.-Atmos., 106, 1005-1016, 2001.

Hess, M., Koepke, P., and Schult, I.: Optical Properties of Aerosols and Clouds: The Software Package OPAC, B. Am. Meteorol. Soc., 79, 831-844, 1998.

Huang, J., Fu, Q., Zhang, W., Wang, X., Zhang, R., Ye, H., and Warren, S. G.: Dust and Black Carbon in Seasonal Snow Across Northern China, B. Am. Meteorol. Soc., 92, 175-181, doi:10.1175/2010BAMS3064.1, 2011.

Jacobson, M. Z.: Climate response of fossil fuel and biofuel soot, accounting for soot's feedback to snow and sea ice albedo and emissivity, J. Geophys. Res.-Atmos., 109, D21201, doi:10.1029/2004JD004945, 2004.

Johnson, B., Turnbull, K., Brown, P., Burgess, R., Dorsey, J., Baran, A. J., Webster, H., Haywood, J., Cotton, R., Ulanowski, Z., Hesse, E., Woolley, A., and Rosenberg, P.: In situ observations of volcanic ash clouds from the FAAM aircraft during the eruption of Eyjafjallajökull in 2010, J. Geophys. Res., 117, D00U24, doi:10.1029/2011JD016760, 2012.

Koerner, R. M.: Distribution of microparticles in a 299-m core through the Devon Island ice cap, Northwest Territories, Canada, Int. Assoc. Hydrol. Sci., 118, 371-376, 1977.

Kohler, J., Brandt, O., Johansson, M., and Callaghan, T.: A longterm Arctic snow depth record from Abisko, northern Sweden, 1913-2004, Polar Res., 25, 91-113, 2006.

Kumai, M.: Electron microscope analysis of aerosols in snow and deep ice cores from Greenland, Isotopes and Impurities in Snow and Ice, IAHS Publ., 118, 341-349, 1977.

Langleben, M. P.: Albedo and degree of puddling of a melting cover of sea ice, J. Glaciol., 8, 407-412, 1969.

Langleben, M. P.: Albedo Of Melting Sea Ice in the Southern Beaufort Sea, J. Glaciol., 10, 101-104, 1971.

Laven, P.: MiePlot: a computer program for scattering of light from a sphere using Mie theory \& the Debye series, PhilipLaven. com $10,2006$. 
Lawrence, C. R. and Neff, J. C.: The contemporary physical and chemical flux of aeolian dust: A synthesis of direct measurements of dust deposition, Chem. Geol., 267, 46-63, 2009.

Laxon, S., Peacock, N., and Smith, D.: High interannual variability of sea ice thickness in the Arctic region, Nature, 425, 947-950, 2003.

Lee Taylor, J. and Madronich, S.: Calculation of actinic fluxes with a coupled atmosphere-snow radiative transfer model, J. Geophys. Res.-Atmos., 107, ACH 22-1-ACH 22-10, 2002.

Libois, Q., Picard, G., Dumont, M., Arnaud, L., Sergent, C., Pougatch, E., Sudul, M., and Vial, D.: Experimental determination of the absorption enhancement parameter of snow, J. Glaciol., 60, 714-724, 2014.

Light, B., Eicken, H., Maykut, G. A., and Grenfell, T. C.: The effect of included participates on the spectral albedo of sea ice, J. Geophys. Res.-Atmos., 103, 27739-27752, 1998.

Marks, A. A. and King, M. D.: The effects of additional black carbon on the albedo of Arctic sea ice: variation with sea ice type and snow cover, The Cryosphere, 7, 1193-1204, doi:10.5194/tc7-1193-2013, 2013.

Marks, A. A. and King, M. D.: The effect of snow/sea ice type on the response of albedo and light penetration depth ( $e$-folding depth) to increasing black carbon, The Cryosphere, 8, 16251638, doi:10.5194/tc-8-1625-2014, 2014.

Maykut, G. A. and Light, B.: Refractive-index measurements in freezing sea-ice and sodium chloride brines, Appl. Optics, 34, 950-961, 1995.

Mishchenko, M. I., Lacis, A. A., Carlson, B. E., and Travis, L. D.: Nonsphericity of dust-like tropospheric aerosols: Implications for aerosol remote sensing and climate modeling, Geophys. Res. Lett., 22, 1077-1080, 1995.

Mishchenko, M. I., Hovenier, J. W., and Travis, L. D.: Light Scattering by Nonspherical Particles, Theory, Measurements, and Applications, Academic Press, San Diego, USA, 1999.

Mishra, S. K. and Tripathi, S. N.: Modeling optical properties of mineral dust over the Indian Desert, J. Geophys. Res.-Atmos., 113, D23201, doi:10.1029/2008JD010048, 2008.

Muñoz, O.: Scattering matrices of volcanic ash particles of Mount St. Helens, Redoubt, and Mount Spurr Volcanoes, J. Geophys. Res., 109, D16201, doi:10.1029/2004JD004684, 2004.

Newman, S. M., Clarisse, L., Hurtmans, D., Marenco, F., Johnson, B., Turnbull, K., Havemann, S., Baran, A. J., O’Sullivan, D., and Haywood, J.: A case study of observations of volcanic ash from the Eyjafjallajökull eruption: 2. Airborne and satellite radiative measurements, J. Geophys. Res., 117, D00U13, doi:10.1029/2011JD016780, 2012.

Nousiainen, T.: Optical modeling of mineral dust particles: A review, J. Quant. Spectr. Ra., 110, 1261-1279, 2009.

Osada, K., Iida, H., Kido, M., Matsunaga, K., and Iwasaka, Y.: Mineral dust layers in snow at Mount Tateyama, Central Japan: formation processes and characteristics, Tellus B, 56, 382-392, doi:10.1111/j.1600-0889.2004.00108.x, 2004.

Pacyna, J. M. and Ottar, B.: Origin of natural constituents in the Arctic aerosol, Atmos. Environ., 23, 809-815, 1989.

Painter, T. H., Skiles, S., Deems, J. S., and Bryant, A. C.: Dust radiative forcing in snow of the Upper Colorado River Basin: 1. A 6 year record of energy balance, radiation, and dust concentrations, Water Resour. Res., 48, W07521, doi:10.1029/2012WR011985, 2012.
Painter, T. H., Barrett, A. P., Landry, C. C., Neff, J. C., Cassidy, M. P., Lawrence, C. R., McBride, K. E., and Farmer, G. L.: Impact of disturbed desert soils on duration of mountain snow cover, Geophys. Res. Lett., 34, L12502, doi:10.1029/2007GL030284, 2007.

Patterson, E. M.: Measurements of the Imaginary Part of the Refractive Index Between 300 and 700 Nanometers for Mount St. Helens Ash, Science, 211, 836-838, 1981.

Patterson, E. M. and Gillette, D. A.: Complex index of refraction between 300 and $700 \mathrm{~nm}$ for Saharan aerosols, J. Geophys. Res., 82, 3153-3160, 1977.

Perovich, D. K.: The Optical Properties of Sea Ice, Monograph 961, US Cold Reg. Res. and Eng. Lab., Philadelphia, USA, 1996.

Perovich, D. K., Maykut, G. A., and Grenfell, T. C.: Optical Properties Of Ice And Snow In The Polar Oceans. I: Observations, 1986 Technical Symposium Southeast, 7 August 1986, Orlando, USA, 0637, 232-241, 1986.

Perovich, D. K., Roesler, C. S., and Pegau, W. S.: Variability in Arctic sea ice optical properties, J. Geophys. Res.-Oceans, 103, 1193-1208, 1998.

Prospero, J. M., Ginoux, P., Torres, O., Nicholson, S. E., and Gill, T. E.: Environmental characterization of global sources of atmospheric soil dust identified with the Nimbus 7 Total Ozone Mapping Spectrometer (TOMS) absorbing aerosol product, Rev. Geophys., 40, 2-1-2-31, 2002.

Purcell, E. M. and Pennypacker, C. R.: Scattering and absorption of light by nonspherical dielectric grains, Astrophys. J., 186, 705714, 1973.

Ram, M. and Gayley, R. I.: Long-range transport of volcanic ash to the Greeland ice sheet, Nature, 349, 401-404, 1991.

Reay, H. J., France, J. L., and King, M. D.: Decreased albedo, efolding depth and photolytic $\mathrm{OH}$ radical and $\mathrm{NO}_{2}$ production with increasing black carbon content in Arctic snow, J. Geophys. Res.-Atmos., 117, D00R20, doi:10.1029/2011JD016630, 2012.

Sarna-Wojcicki, A. M., Shipley, S., Waitt Jr., R. B., and Dzurisin, D.: Areal distribution, thickness, mass, volume, and grain size of air-fall ash from the six major eruptions of 1980, U.S. Geol. Surv. Prof. Pap., 1250, 577-600, 1981.

Schwikowski, M., Seibert, P., Baltensperger, U., and Gaggeler, H. W.: A study of an outstanding Saharan dust event at the high-alpine site Jungfraujoch, Switzerland, Atmos. Environ., 29, 1829-1842, 1995.

Serreze, M. C. and Barry, R. G.: The Arctic Climate System, Cambridge Atmospheric and Space Science Series Publisher Cambridge University Press, Cambridge, UK, ISBN 0521116007, 9780521116008, 404 pp., 2005.

Shaw, G. E.: Microparticle size spectrum of Arctic haze, Geophys. Res. Lett., 11, 409-412, 1984.

Sokolik, I. and Toon, O. B.: Modeling the radiative characteristics of airborne mineral aerosols at infrared wavelenghts, J. Geophys. Res., 103, 8813-8826, 2007.

Sokolik, I., Andronova, A., and Johnson, T. C.: Complex refractive index of atmospheric dust aerosols, Atmos. Environ. Part A General Topics, 27, 2495-2502, 1993.

Stamnes, K., Tsay, S.-C., Wiscombe, W., and Jayaweera, K.: Numerically stable algorithm for discrete-ordinate-method radiative transfer in multiple scattering and emitting layered media, Appl. Optics, 27, 2502-2509, 1988. 
Stone, R. S., Key, J. R., and Dutton, E. G.: Properties and decay of stratospheric aerosols in the Arctic following the 1991 eruptions of Mount Pinatubo, Geophys. Res. Lett., 20, 2359-2362, 1993.

Tegen, I. and Fung, I.: Modeling of mineral dust in the atmosphere: Sources, transport, and optical thickness, J. Geophys. Res.-Atmos., 99, 22897-22914, 1994.

Thompson, L.: Variations in microparticle concentration, size distribution and elemental composition found in Camp Century, Greenland, and Byrd station, Antarctica, deep ice cores, in: Proceedings of symposium on isotopes and impurities in snow and ice, International Association of Hydrological Sciences, Commission of snow and ice, I.U.G.G., XVI, General Assembly, Grenoble, France, August-September 1975, Washington DC, USA, 351-363, 1977.

Thorsteinsson, T., Johannsson, T., Stohl, A., and Kristiansen, N. I.: High levels of particulate matter in Iceland due to direct ash emissions by the Eyjafjallajokull eruption and resuspension of deposited ash, J. Geophys. Res.-Solid Earth, 117, B00C05, doi:10.1029/2011JB008756, 2012.

Toon, O. B., McKay, C. P., Ackerman, T. P., and Santhanam, K.: Rapid calculation of radiative heating rates and photodissociation rates in inhomogeneous multiple scattering atmospheres, J. Geophys. Res.-Atmos., 94, 16287-16301, 1989.

Turnbull, K., Johnson, B., Marenco, F., Haywood, J., Minikin, A., Weinzierl, B., Schlager, H., Schumann, U., Leadbetter, S., and Woolley, A.: A case study of observations of volcanic ash from the Eyjafjallajökull eruption: 1. In situ airborne observations, J. Geophys. Res., 117, D00U12, doi:10.1029/2011JD016688, 2012.

VanCuren, R. A., Cahill, T., Burkhart, J., Barnes, D., Zhao, Y., Perry, K., Cliff, S., and McConnell, J.: Aerosols and their sources at Summit Greenland - First results of continuous size- and timeresolved sampling, Atmos. Environ., 52, 82-97, 2012.

Wang, X., Doherty, S. J., and Huang, J.: Black carbon and other light-absorbing impurities in snow across Northern China, J. Geophys. Res.-Atmos., 118, 1471-1492, doi:10.1029/2012JD018291, 2013.

Warren, S. G.: Optical properties of snow, Rev. Geophys., 20, 6789, 1982.

Warren, S. G.: Impurities in snow: effects on albedo and snow melt (Review), Ann. Glaciol., 5, 177-179, 1984.

Warren, S. G. and Brandt, R. E.: Optical constants of ice from the ultraviolet to the microwave: A revised compilation, J. Geophys. Res.-Atmos., 113, D14220, doi:10.1029/2007JD009744, 2008.

Warren, S. G. and Clarke, A. D.: Soot in the atmosphere and snow surface of Antarctica, J. Geophys. Res.-Atmos., 95, 1811-1816, 1990 .
Warren, S. G. and Wiscombe, W. J.: A Model for the Spectral Albedo of Snow. II: Snow Containing Atmospheric Aerosols, J. Atmos. Sci., 37, 2734-2745, 1980.

Warren, S. G., Rigor, I. G., and Untersteiner, N.: Snow depth on Arctic sea ice, J. Climate, 12, 1814-1828, 1999.

Weeks, W.: On Sea Ice, University of Alaska Press, Fairbanks, Alaska, USA, 2010.

Westphal, D. L., Toon, O. B., and Carlson, T. N.: A two-dimensional numerical investigation of the dynamics and microphysics of Saharan dust storms, J. Geophys. Res.-Atmos., 92, 3027-3049, 1987.

Wiscombe, W. J. and Warren, S. G.: A Model for the Spectral Albedo of Snow. I: Pure Snow, J. Atmos. Sci., 37, 2712-2733, 1980.

Woo, M.-K. and Dubreuil, M.-A.: Empirical relationship between dust content and Arctic snow albedo, Cold Reg. Sci. Technol., 10, 125-132, 1985.

Yasunari, T. J., Lau, K. M., Mahanama, S., and Colarco, P. R.: The GOddard SnoW Impurity Module (GOSWIM) for the NASA GEOS-5 Earth System Model: Preliminary Comparisons with Observations in Sapporo, Japan, SOLA, 2014.

Ye, H., Zhang, R., Shi, J., Huang, J., Warren, S. G., and $\mathrm{Fu}, \mathrm{Q}$.: Black carbon in seasonal snow across northern Xinjiang in northwestern China, Environ. Res. Lett., 7, 044002, doi:10.1088/1748-9326/7/4/044002, 2012.

Young, C. L., Sokolik, I. N., and Dufek, J.: Regional radiative impact of volcanic aerosol from the 2009 eruption of Mt. Redoubt Atmos. Chem. Phys., 12, 3699-3715, doi:10.5194/acp-12-36992012, 2012.

Zdanowicz, C. M., Zielinski, G. A., and Wake, C. P.: Characteristics of modern atmospheric dust deposition in snow on the Penny Ice Cap, Baffin Island, Arctic Canada, Tellus B, 50, 506-520, 1998.

Zhang, R., Hegg, D. A., Huang, J., and Fu, Q.: Source attribution of insoluble light-absorbing particles in seasonal snow across northern China, Atmos. Chem. Phys., 13, 6091-6099, doi:10.5194/acp-13-6091-2013, 2013.

Zhao, C., Hu, Z., Qian, Y., Ruby Leung, L., Huang, J., Huang, M., Jin, J., Flanner, M. G., Zhang, R., Wang, H., Yan, H., Lu, Z., and Streets, D. G.: Simulating black carbon and dust and their radiative forcing in seasonal snow: a case study over North China with field campaign measurements, Atmos. Chem. Phys., 14, 1147511491, doi:10.5194/acp-14-11475-2014, 2014.

Zielinski, G. A., Mayewski, P. A., Meeker, L. D., Grönvold, K., Germani, M. S., Whitlow, S., Twickler, M. S., and Taylor, K.: Volcanic aerosol records and tephrochronology of the Summit, Greenland, ice cores, J. Geophys. Res.-Oceans, 102, 2662526640, 1997. 